OECD "Better Policies" Series

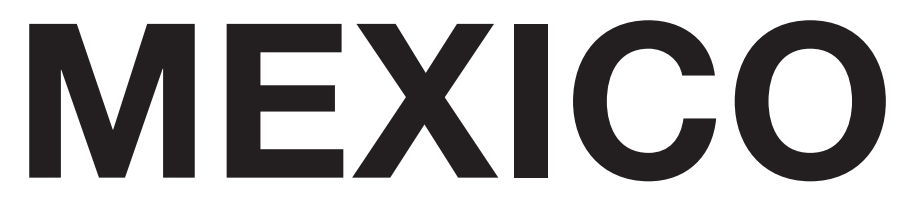

BETTER POLICIES FOR

INCLUSIVE DEVELOPMENT

\title{
SEPTEMBER 2012
}

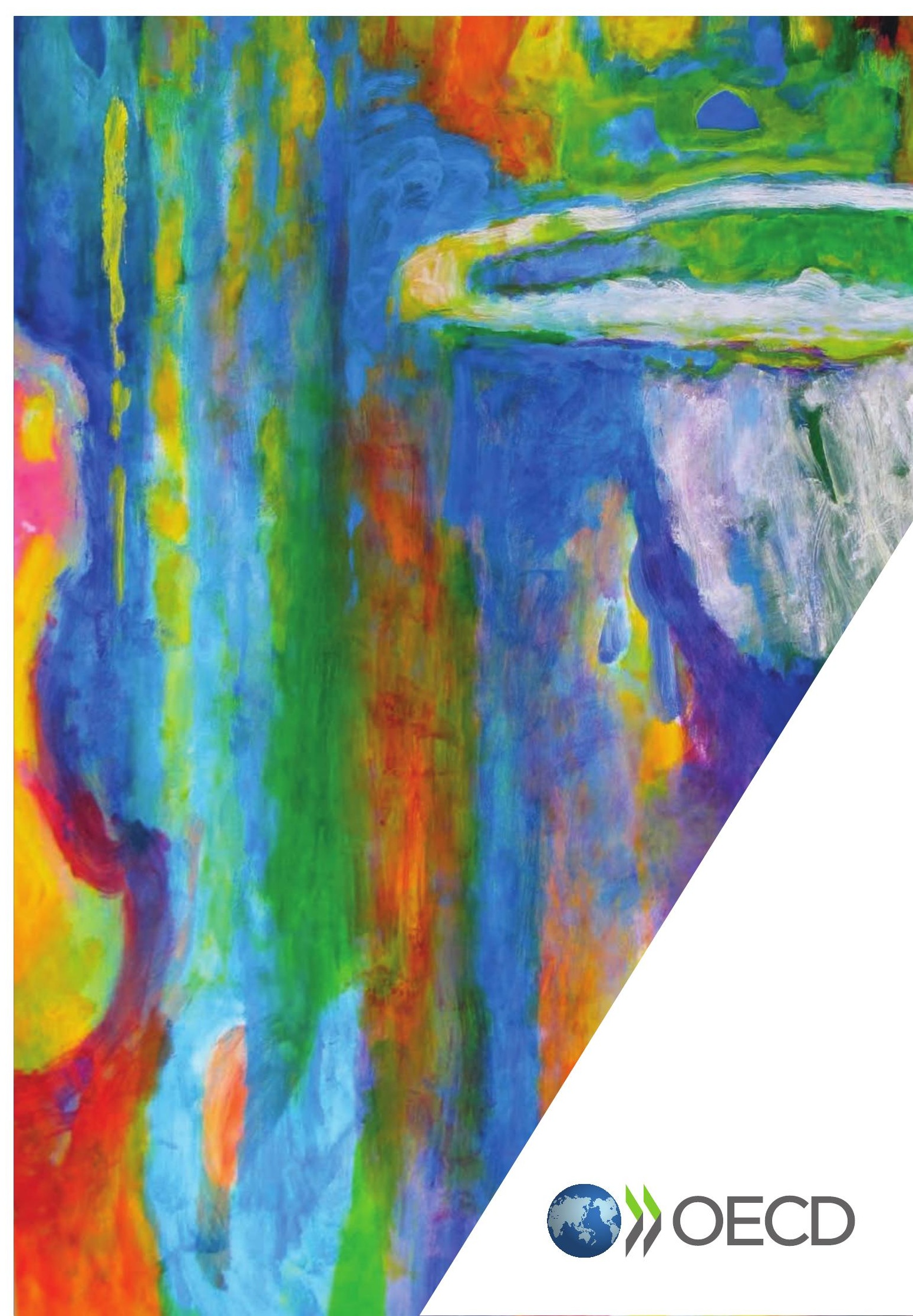



Better Policies

\section{Mexico: Better Policies for Inclusive Development}


This work is published on the responsibility of the Secretary-General of the OECD. The opinions expressed and arguments employed herein do not necessarily reflect the official views of the Organisation or of the governments of its member countries.

This document and any map included herein are without prejudice to the status of or sovereignty over any territory, to the delimitation of international frontiers and boundaries and to the name of any territory, city or area.

ISBN 978-92-64-20168-2 (PDF)

Series: Better Policies

ISSN 2308-1392 (online)

The statistical data for Israel are supplied by and under the responsibility of the relevant Israeli authorities. The use of such data by the OECD is without prejudice to the status of the Golan Heights, East Jerusalem and Israeli settlements in the West Bank under the terms of international law.

Photo credits: Cover $\odot$ Painting by Mexican artist Carlos Torres

Corrigenda to OECD publications may be found on line at: www.oecd.org/publishing/corrigenda.

(c) OECD 2013

You can copy, download or print OECD content for your own use, and you can include excerpts from OECD publications, databases and multimedia products in your own documents, presentations, blogs, websites and teaching materials, provided that suitable acknowledgment of the source and copyright owner is given. All requests for public or commercial use and translation rights should be submitted to rights@oecd.org. Requests for permission to photocopy portions of this material for public or commercial use shall be addressed directly to the Copyright Clearance Center (CCC) at info@copyright.com or the Centre français d'exploitation du droit de copie (CFC) at contact@cfcopies.com. 


\section{Table of Contents}

Foreword 3

1. Growth Potential 5

2. Combating Poverty and Inequality 8

3. Fiscal Challenges in the Short and Medium Term 11

4. Reforming the Tax System for Growth and Equity 14

5. The Efficiency of Public Administration 17

6. Regional Disparities 21

7. The Labour Market $\quad 25$

8. The Education System 28

9. Health Challenges 32

10. Gender Equality 35

11. Innovation 38

12. Integrating Mexico into the World Economy through

Trade and FDI 40

13. Competition and Tackling Public and Private Monopolies 43

14. The Telecommunications Sector 46

15. Regulatory Policy 49

16. The Business Environment 52

17. Green Growth 55

18. Energy Policy 58

19. The Agriculture Sector and Rural Areas 63

20. Water Management 66

21. Security and its Economic Impact 68 



\section{Foreword}

If opportunity really does flourish in situations of uncertainty, then we have entered a phase of opportunities. The global economy is in its fifth year of crisis and still suffering from the perverse effects of the "Great Recession". In many OECD countries, economic growth remains anaemic; public finances are weak; unemployment, particularly among young people, remains at record levels, while inequalities continue to grow. The situation is particularly worrying in Europe, where the loss of confidence among firms, households and financial markets continues to impair growth that has already been undermined by various simultaneous fiscal consolidation processes.

The large emerging economies have also been running out of steam. Simultaneous slowdowns among countries such as Brazil, China, India and Russia show that in a globalised economy interdependence is an inescapable fact; what makes it even worse is that slower growth in these countries threatens to undermine their efforts to reduce poverty. Although economic performance in developing countries remains well above the OECD average, global economic growth in 2012 will barely reach 3.5\%.

In this uncertain and complex context, buffeted by winds of change, Mexico is going through a major political transition, having elected a new president who will take office on 1 December 2012. The start of this new cycle gives the country a great opportunity to consolidate its progress and speed up convergence towards higher levels of welfare.

Unlike what happens in many other countries, the new Mexican government will start out with sound public finances, controlled inflation, a growth rate that is double the OECD average, a well capitalised banking system, a network of trade agreements with 44 countries, and regulatory improvements that enhance the business climate. At the same time, the country faces very major challenges in terms of economic competitiveness and social inclusion. All of this is unfolding as transnational firms are seeking new markets and investment platforms to make up for the slowdown in developed countries and rising production costs in direct competitors such as China. Mexico needs to exploit this combination of strengths and circumstances to raise its "cruising speed", increase its competitiveness, and reduce poverty.

To achieve this, Mexico must address a number of structural challenges and improve its productivity, by implementing reforms in strategic areas. It urgently needs to build a robust, streamlined and redistributive tax system; a state-of-the-art and equitable education system, with teachers and schools of the highest quality; a budgeting process targeted on medium- and long-term outcomes; an effective, fair and reliable rule of law; a new, more modern and inclusive labour law; a set of regulations and incentives to promote competition; a national innovation system that stimulates growth through knowledge; a green growth strategy; a strategic energy plan with a long-term vision; a high-quality, inclusive and sustainable health system; and new instruments to measure the welfare of Mexican people and target public policies more effectively. 
The OECD provides a forum for countries to share experiences, coordinate their efforts and explore solutions in these and other areas. Its aim is to help design better policies for better lives. Based on that knowledge and on rigorous comparative international analysis, this document sets out our main thinking and recommendations in areas that are strategic for Mexico's present and future.

The analysis that is being delivered today to President-elect Enrique Peña Nieto, is the preamble to a broaderscope exercise in which the OECD will work with the new administration's transition teams to produce a study on "Public policy challenges in Mexico". This will draw on the Organisation's work with Mexico and other countries, and at the same time it will be the basis for a public policy forum with national and international experts to be held in Mexico City in January 2013. All of this is intended as an input for preparing the government's plan for the next six years and to identify its sources of financing.

This cooperation modality has also been implemented with other OECD countries in the context of the Getting it Right series of studies, in support of transition processes in those countries. The OECD is privileged to undertake this effort with the new Mexican government. We hope this document and the work to follow will help design, promote and successfully implement the changes that Mexico needs to build a more prosperous, greener and fairer country.

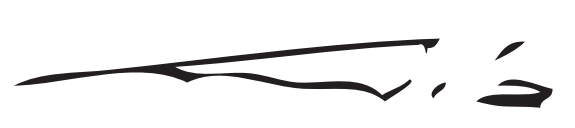

\section{Angel Gurría}

OECD Secretary-General

Mexico City, 11 September 2012 


\section{Growth Potential}

Convergence of Mexico towards average OECD living standards has been slow. The country has many strengths it can draw upon to boost growth potential, including plentiful natural resources, a young dynamic population, a high degree of trade openness, and the fact that it shares a long border with the world's largest economy. It has also made considerable progress in improving health and education coverage, and promoting competition; and it is now implementing one of the most innovative and successful poverty-reduction programmes in the world. Nonetheless, important bottlenecks remain that prevent Mexico from making the most of its abundant assets. More reform is needed.

Virtually, almost all the gap between Mexico and OECD countries stems from lower labour productivity. The need for structural reforms to raise productivity is reinforced by the pressures the country faces as other labourintensive economies increase their participation in the world economy, which makes it even more urgent for Mexico to improve its position in global value chains and produce goods of higher value-added.

The OECD estimates that a moderate reform program could enhance Mexico's potential growth rate by about one half of a percentage point, from its current level of around $3 \%$ per year, thanks to an increasingly positive contribution from productivity, which in recent years has tended to be negative (Figure 1.1).

In the medium term, these growth rates could be raised to at least $4 \%$ per year on a sustained basis, depending on the intensity of the reforms, particularly if the quality of Mexico's regulation exceeds the OECD average and approaches that of the best performing OECD economies. Progress on this scale would help to increase Mexico's per capita income from its current level, close to a quarter of that of the United States, to almost half of the U.S. level by the end of the projection horizon (2030).

Boosting productivity is, therefore, the key to raise the growth rate. This requires major structural reforms particularly to strengthen the education system, revise overly stringent formal job protection, strengthen competition in key network industries, remove barriers to foreign direct investment, strengthen the legal system, and increase government revenues. In addition to making the domestic economy more competitive, these reforms would make it possible to increase employment, reduce informality and inequality, and enhance the welfare of the Mexican people.

The education system in particular needs in-depth reform. This is a domain that could bring large benefits in terms of higher productivity, through higher educational achievement and human capital that is better matched to labour-market needs. However, weaknesses in educational enrolment and quality, particularly at junior high school, senior high school and higher education, limit the potential contribution of human capital to the economy. Still worse, it is a regrettable waste, given the country's demographic profile, which provides a window of opportunity in the next few years. National standards need to be applied to teacher performance, 
Figure 1.1. GDP Potential growth under different reform scenarios

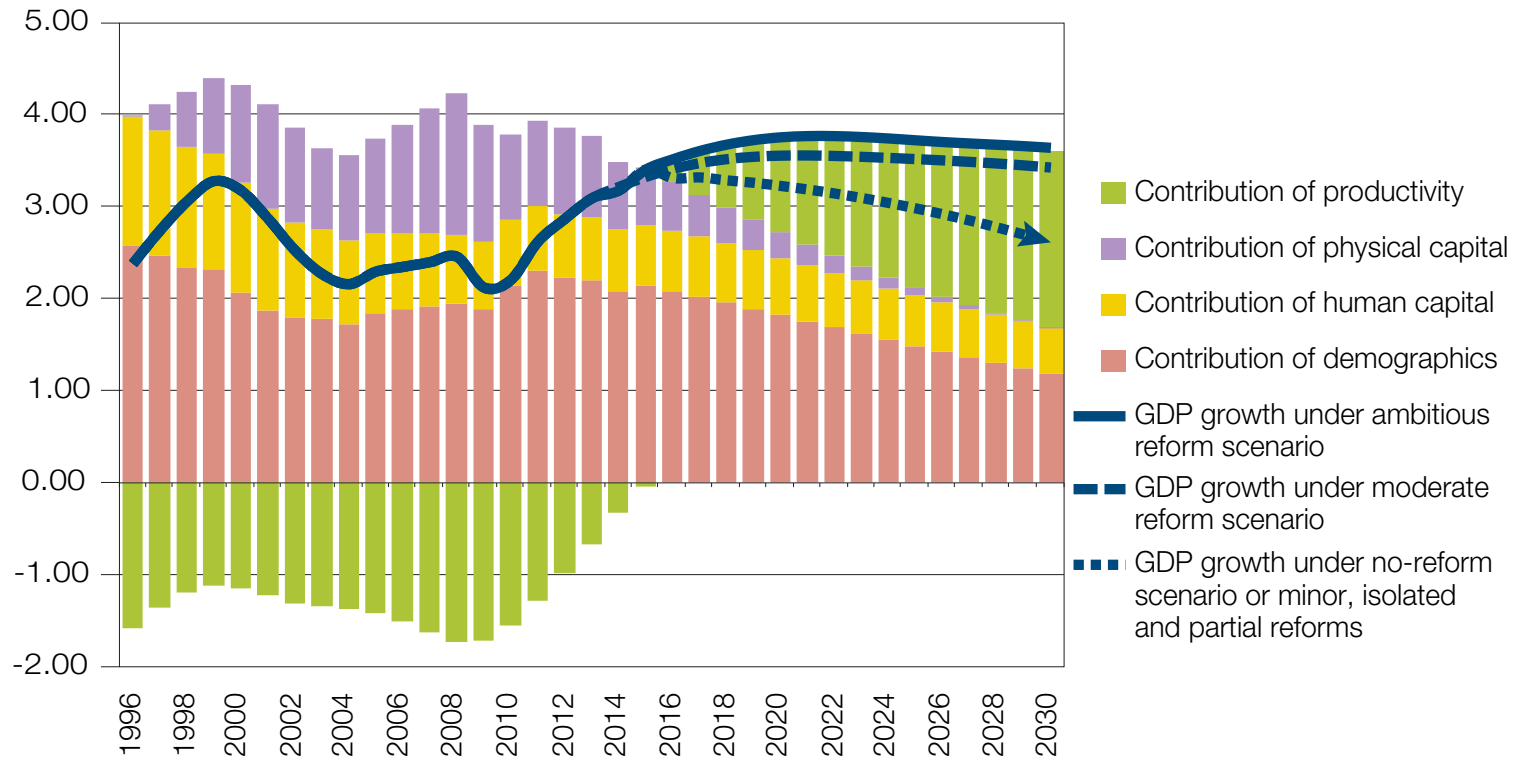

Source: OECD Economic Outlook database and OECD analysis.

to ensure the quality of teaching and to have incentives for continuous improvement; and the training of school management needs to be professionalised, and schools must be provided with reliable financing through a more efficient allocation of local funding and resources.

The labour market is another area requiring a new approach. Its dual nature, with high protection in one segment but high levels of informality in the other, impairs productivity growth and thus increases inequality. Hiring and firing costs need to be reduced, through shorter-term contracts, and a simplification of employment litigation to provide greater certainty to all parties. Training and hiring policies need also to be formulated to encourage greater investment in workers, while also strengthening social security systems. The labour reform project submitted to the Mexican Congress last year could serve as a basis for debate on these major challenges.

Restrictions on foreign direct investment in services and infrastructure are among the most stringent ones in the OECD, harming competition, trade and investment that could help to boost capital accumulation and productivity.

Entry barriers in the network industries provide a clear example of this problem. Costly registration procedures and the limited contestability in key network sectors, notably the telecom and oil \& gas sectors, limit investment and productivity. Openness to private investment in the oil sector -as is the case almost throughout the world, even in countries whose oil companies are under state control, such as Brazil - could provide a major source of capital accumulation and facilitate growth of the PEMEX oil production platform.

Although reforms are being implemented to make it easier to start up new businesses, the lack of effectiveness, promptness and certainty of the legal system impair the efficacy of contracts and the security of property rights, reducing economies of scale, limiting investment and efficiency. Major reforms have been initiated to improve the accountability and professionalism of the judiciary, particularly by applying oral proceedings, but in many states this has not yet been implemented and in others implementation leaves much to be desired. Reforms 
are also needed at the federal level, for instance to revise the amparo system of injunctions, to strengthen competition in some network sectors where these are used to obstruct regulators actions.

Tax reform, reducing Mexico's dependency on oil revenues, and improving safety nets would also help to reduce uncertainty, strengthen overall economic performance, and reduce poverty. Fiscal reforms to boost non-oil revenues and create buffers to absorb fluctuations in tax revenues would play a key role in this respect.

Mexico continues to display major income inequalities, both across regions and between genders. Reducing inequality and promoting inclusion should be a priority on the reform agenda. This is important not only for welfare reasons but also because more inclusive societies tend to perform better. Some policies have dual dividends in terms of boosting growth potential and also reducing inequality - for example, a labour market reform which would help to create more jobs, to share the gains of openness and trade more widely and to improve the quality of new jobs. Another example would be improving the quality and equity of the education system. Other reforms, such as the removal of energy subsidies or broadening of tax bases, will require compensation schemes to protect the poorest and mechanisms to ensure that all states benefit from reforms and enjoy higher living standards.

Lastly, stronger growth needs to be complemented with specific policies on biodiversity, water, energy efficiency and the environment to promote greener growth.

\section{Key OECD recommendations}

- Remove persistent obstacles to productivity growth by promoting competition in product and services markets, reducing entry barriers - particularly for foreign firms in network sectors, notably electricity, telecommunications and infrastructure, and improving the rule of law.

- Further improve the quality and equity of education, strengthening the professional training and education of teachers and school management, among other areas.

- Promote labour market reform to encourage job creation and reduce informality.

- Undertake structural fiscal reform to secure greater competitiveness, higher non-oil tax revenues and more solid stabilisation mechanisms.

- Ensure that policies are inclusive, that compensation schemes are set up for the poorest when necessary, and fiscal federalism is improved. 


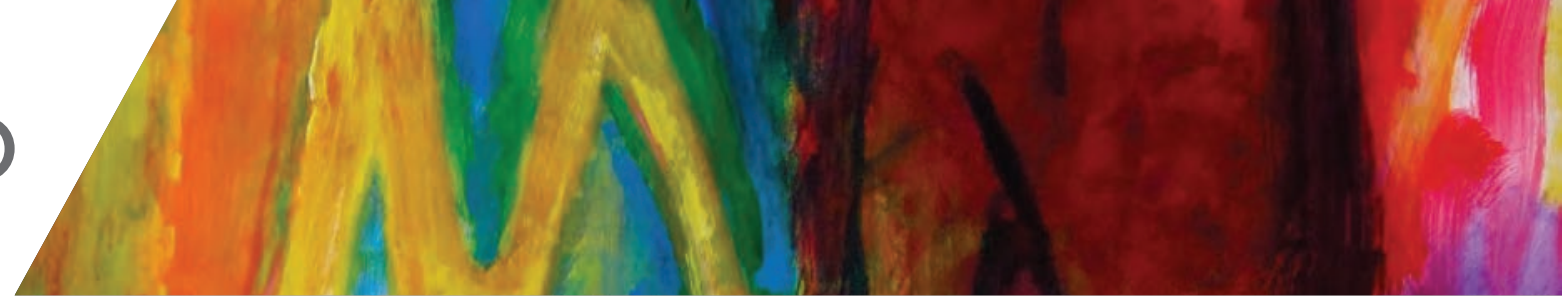

\section{Combating Poverty and Inequality}

Mexico has implemented major initiatives to tackle poverty. Progresa, introduced in 1997, and Oportunidades, introduced in 2002, are two of the most innovative and successful programmes for reducing extreme poverty, reaching over 5.8 million Mexican families by 2011. Oportunidades has contributed to a reduction of poverty, higher school attendance, fighting malnutrition and to extend health coverage to poor families. Another initiative, Seguro Popular, introduced in 2004, is designed to provide medical care, preventive services and financial protection for people without health coverage. At the end of 2011, it was providing free health coverage to over 50 million people, mostly those in the bottom two income deciles. This program is also helping to gradually reduce the wide regional disparities in access to health services.

\section{Despite progress, poverty remain widespread and inequalities are very large}

Despite these successful initiatives, the fight against poverty and inequality needs to continue. Although poverty had been declining over the past few decades, it has increased since the mid-2000s first because of soaring food prices and then as a result of the global crisis and the fall in formal employment. Recent data from the Consejo Nacional de Evaluación de la Política de Desarrollo Social, CONEVAL, show that between 2006 and 2010 , the proportion of people in poverty (extreme and moderate) increased from $35 \%$ to $46 \%$, equivalent to 52 million people. The indicator of relative poverty in relation to the average income of the population, used internationally as a comparison benchmark, shows that in Mexico $21 \%$ of the population received less than half the average income in 2010. This indicator also shows that poverty among the elderly is an urgent issue, affecting $30 \%$ of Mexicans older than 75 (a rate 1.5 greater than the population as a whole). As the population is aging, there is a risk that the proportion of elderly poor will increase further.

The high level of poverty is also reflected in other standard of living indicators, such as child mortality (three times higher than the OECD average) and the illiteracy index (above the OECD average). Mexico has the highest index of child poverty in the OECD after Israel. As its population is comparatively young and children account for almost half of all the poor, poverty in Mexico has longer term consequences than in other OECD countries.

Although Mexico is one of the few OECD countries in which inequalities have actually decreased in recent decades, their level remains very high. Mexico is the second most unequal country in the OECD after Chile. This is not only an ethical and moral problem, but represents an obstacle to growth and development. OECD data, published in Divided We Stand: Why Inequality Keeps Rising (December, 2011), show that the bottom $10 \%$ of the distribution in Mexico receives around $1.3 \%$ of total disposable income, while the wealthiest $10 \%$ receives close to $36 \%$ (Figure 2.1). 
Figure 2.1. Income inequality (Gini coefficient)

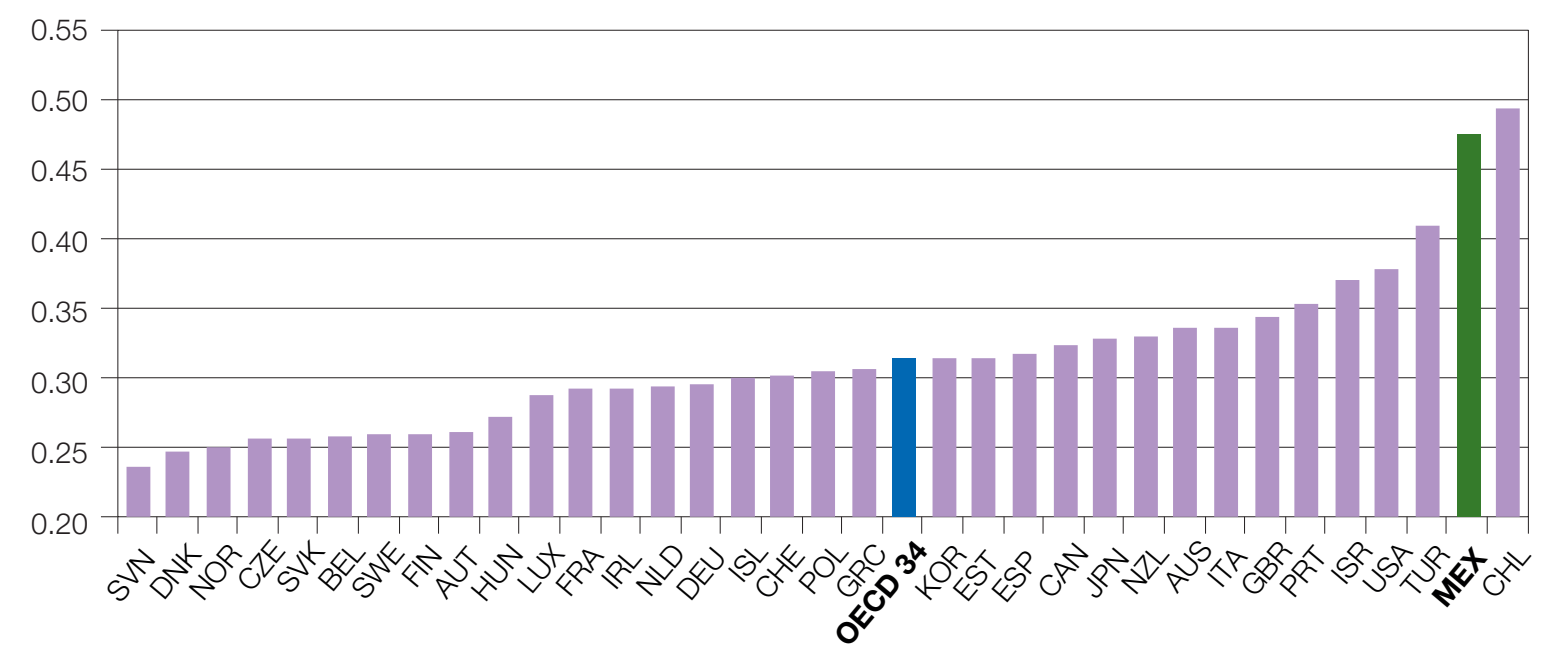

Source: OECD income distribution questionnaire (2011).

\section{Increasing and better targeting social spending}

Although public social spending grew from less than 2\% of GDP in 1985 to $7.5 \%$ in 2009 (excluding expenditure on education), this amounts to about a third of the OECD countries average (Figure 2.2), and it is still low in relation to per capita GDP. Cash social transfers only account for about $8 \%$ of household disposable income. Moreover, this spending is not well targeted: half of the cash transfers benefits people at the higher end of the distribution and only about $10 \%$ of the funds are received by the poorest $20 \%$. If poverty is to be reduced significantly, social transfers to the poorest must increase, and this requires reforming the social security system with a view to providing more effective and progressive support to the lowest-income families.

To respond to economic downturns more promptly and avoid the risk of moderately poor families falling into extreme poverty (which is quite large in Mexico as the wage level of most middle-class people is closer to the wages of workers at the bottom of the distribution than to those at the top), Mexico needs to strengthen social safety nets. The measures introduced by the government in response to the global economic crisis include programmes to provide temporary employment and prevent job losses (Programa de Empleo Temporal), as well as schemes extending health coverage for the unemployed by several months. However, the amounts channelled into these programs are modest. This underscores the scope available for better tailored countercrisis measures to protect poor families in Mexico - by increasing the focus on temporary employment programmes, for example. There is also room to support formal employment and make unemployment benefit programmes more effective. The Primer Empleo programme did not have the expected impact to stimulate formal employment, because of the limited capacity to provide incentives for employers to hire new workers (see chapter 7).

Curbing poverty and reducing inequality will also require improving further the quality of education and health services (see chapters 8 and 9), since it has already been made in coverage. 


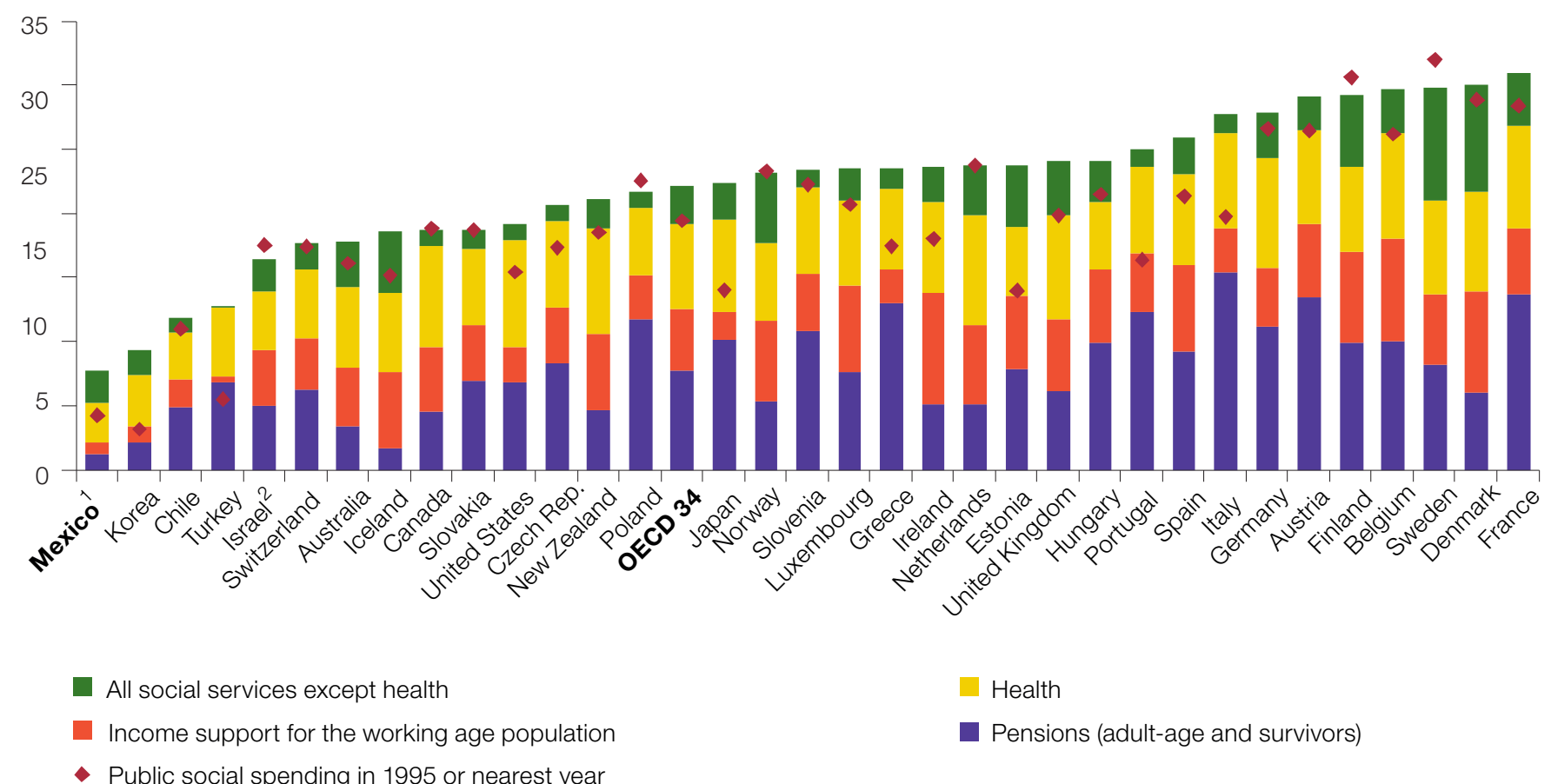

1 The figures for Mexico have been calculated, and the reference year for Switzerland is 2008.

2 Information on data for Israel: http://dx.doi.org/10.1787/888932315602

Source: Preliminary figures, OECD (2012) Social Expenditure database (SOCX), www.oecd.org/els/social/expenditure

\section{Key OECD recommendations}

- Increase social spending. Gradually approach it to the levels of other OECD countries, through greater investments in quality education, health and transfers targeted on the poorest population.

- Replace subsidies with cash transfers for the poorest. Review the effectiveness of programmes - such as DICONSA (Distribuidora Conasupo Sociedad Anónima, providing essential goods to rural communities) and LICONSA (Leche Industrializada Conasupo Sociedad Anónima) - and streamline the numerous social programmes to avoid overlap and exploit synergies.

- Analyse the mix of interventions designed to reduce rural poverty and promote rural development.

- Implement measures to expand job opportunities in the formal economy and create incentives so workers seek formal-sector jobs.

Enhance the productivity in health services to enable them to provide higher-quality services at a lower cost.

- Improve the quality of education services to increase human capital, promote social mobility, and reduce inequalities. 


\section{Fiscal Challenges in the Short and Medium Term}

After the economic stimulus based on more government spending in 2009, the government tightened its tax policy, raised taxes, and curtailed expenditure growth. As a result, the public sector net borrowing requirements -a measure of the combined deficit of the federal government and its public enterprises - declined from around 5\% of GDP in 2009 to 3\% of GDP in 2012 (Figure 3.1). The government intends to continue limiting spending growth and reduce the public sector borrowing requirements to around $2 \%$ of GDP in 2013. This would translate into a closing of the nominal deficit, based on the government's definition, which excludes PEMEX financing but includes other financial operations. Although the planned fiscal consolidation has been delayed somewhat by the international economic slowdown, this is not a major concern since debt and deficit are moderate and a gradual consolidation is taking place. If the recovery unfolds as projected, the government will be able to implement its consolidation plans in full to avoid eroding market confidence in Mexico's fiscal policy. Nonetheless, structural fiscal reforms are necessary to boost sustainable and inclusive long-term growth.

\section{Improving the fiscal framework}

Further tax and oil sector reforms are needed to make the budget less dependent on volatile oil revenues, while maintaining oil production. The low investment capacity of the state-owned oil company, PEMEX, given the current fiscal framework, limits its ability to increase production. Maintaining current production levels beyond the next 10 years would require large-scale investments to identify new oil fields. In 2008, the Mexican government has also taken initial steps to make PEMEX's contracting mechanisms more flexible to enable it to work more like its peers. But the outlook for oil revenues remains uncertain and therefore a strategy to strengthen non-oil tax revenues is needed (see chapter 4). The country also needs to reduce the high cost of energy subsidies, which place a heavy burden on the budget, and are socially regressive and environmentally harmful. Withdrawing the subsidies and replacing them with well targeted cash transfers would be more efficient as a means to combat poverty and would avoid distorting prices and harming the environment (see chapter 17).

In addition, GDP deviations from its trend have been higher in Mexico than in virtually all other OECD countries, even during the recent recession. The gap between actual GDP and potential GDP widened by 10 percentage points from the first quarter of 2008 to the first quarter of 2009; and real GDP fell by 6\% in 2009 against an OECD average of $3.5 \%$.

In Mexico, this volatility in GDP growth can have large costs for individuals and for long-term economic growth. As a large share of the population is credit-constrained and their social safety net is weak, temporary disruptions in output tend to be accompanied by falls in consumption and welfare. 
Figure 3.1. Mexico's fiscal balance and gross debt
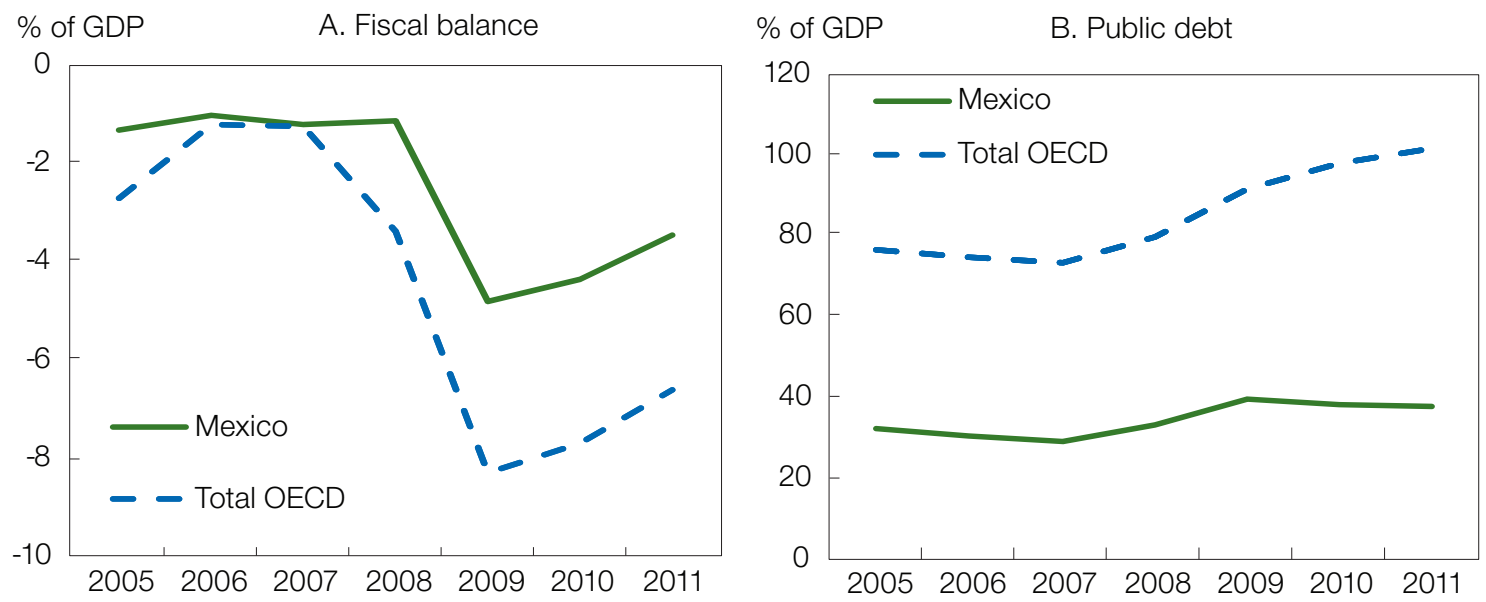

Notes: The fiscal balance is the public sector net borrowing requirements (PSBR), including the central government and public enterprises, as a percentage of nominal GDP. Gross debt is the historical balance of the public sector net borrowing requirements, as a percentage of nominal GDP.

Source: OECD Economic Outlook 91 database and Fiscal Consolidation Survey 2012.

Sharp deviations of GDP from its trend and the associated spells of unemployment and poverty can also have adverse effects on long-term economic growth through hysteresis effects or by greater uncertainty. These large fluctuations could be avoided by further improving the fiscal policy framework to strengthen fiscal buffers, to mitigate the impact of fluctuations in tax revenue, by setting aside a larger amount of fiscal resources during economic upturns and periods of high oil prices to respond to unexpected negative shocks. Accumulating a financial buffer would also help to prepare for the ageing of Mexico's population, which will increase health expenditures of the social security institutes (IMSS and ISSSTE) and Seguro Popular.

The Mexican government could adopt a balanced structural budget rule that takes account of the cyclical nature of tax and oil revenues, following the example of Chile. Such a rule would be more effective if government accounts were presented according to international standards for national accounts, because currently it is difficult to identify strictly transitory income (such as oil price hedging) and some financing operations are reported as income. The revenue surpluses accruing during economic upswings or periods of high oil prices should then be accumulated in a stabilization fund. With simple and transparent rules on savings and withdrawals, this would enhance the transparency of oil revenue management. A system of revenue stabilization funds already exists in Mexico, but the rules on savings and withdrawals are complex and the ceilings imposed on these funds are moderate. This resulted in the accumulation of less than $2 \%$ of GDP even in periods of high oil prices. In the case of Chile, its structural budget surplus rule of $1 \%$ of GDP enabled it, between 2001 and 2007, to accumulate reserves amounting to 20\% of GDP at the start of the crisis in 2008, which could be used to provide a major fiscal stimulus. By the first quarter of 2012, the copper fund amounted to $5.8 \%$ of GDP. In Norway, the state pension fund was worth $119 \%$ of total GDP in the first quarter of 2012. As a first step towards the establishment of a full-fledged economic stabilization fund, the temporary lifting of the limits on accumulated assets in the oil stabilization funds (in 2010 and 2011) should be made permanent. 


\section{Securing fiscal discipline at the sub-national levels}

Despite improvements in the past decade, instruments to secure fiscal discipline at the sub-national level are weak. Although by international comparison, sub-national government debt is moderate, it has grown rapidly over recent years. Rules were introduced in 2000 to limit states' access to borrowing, increase transparency, as well as to strengthen the federal government's commitment not to bail out sub-national institutions. However, the current asymmetry between federal transfers and internally generated tax revenues can still lead to "soft" budget constraints and moral hazard. The federal government should promote the implementation of prudent fiscal rules at the sub-national level. The implicit liabilities arising from the civil service pension scheme are also high; and several states have recently introduced pension pillars which are highly unsustainable, since they are financed through taxes alone, rather than on the basis of worker and employer contributions. Addressing this challenge will require in-depth reforms, including converting the defined benefit pension systems remaining in most states to defined contribution systems based on individual accounts similar to the AFORES. Efforts to improve the quality and timeliness of local government fiscal accounts should proceed as planned. Further information on states' debt, and contingent liabilities, would help improve transparency and accountability, in addition to better monitoring of the sustainability of public finances.

\section{Key OECD recommendations}

- Implement the current consolidation plans in full if the economic recovery unfolds smoothly.

- Improve the governance and operating efficiency of PEMEX, by lifting investment constraints and strengthening accountability.

- Tackle output volatility by further improving the fiscal policy framework, and accumulating fiscal buffers to mitigate the impact of fluctuations, which could be usefully accomplished using a structural balance rule.

- Report government accounts using official national accounts standards, clearly identifying transitory income and avoiding reporting financing operations as income, to enhance comparability and facilitate the application of a structural fiscal rule.

- Promote the implementation of prudential limits on borrowing at the sub-national level and work with states to complete the transition from defined-benefits to definedcontribution pensions. 
Figure 4.1. Gini coefficients (inequality) before and after taxes and transfers

Market income

After taxes and transfers
Market income

$x+$ Education (in-kind)
+ Cash transfers

$\Delta+$ Health (in-kind)

Income tax
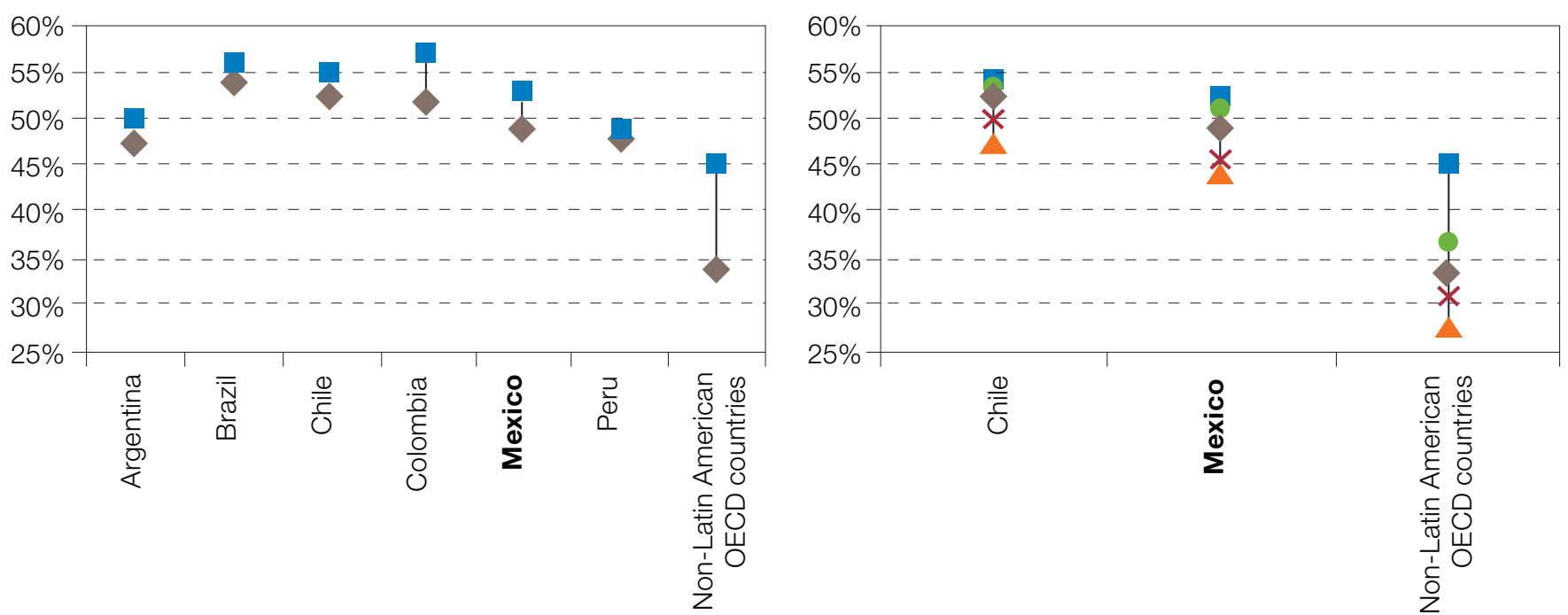

Source: OECD Latin American Economic Outlook 2012.

In addition to the withdrawal of energy subsidies advocated in chapter 3 , the creation of a broad-based greenhouse gas emission tax would help secure revenues while promoting green growth.

\section{Improving sub-national tax collection}

The overall share of tax revenue collected by sub-national governments in Mexico is among the lowest in the OECD. There is a need to strengthen incentives for the states to collect revenues by limiting federal government transfers and allowing higher marginal revenue retention. Incentives for states to retain more revenues and exert greater tax authority are not incompatible with the development of a transparent and fair equalisation mechanism that would ensure that less wealthy states have the necessary resources to ensure income convergence (see chapter 6). The municipalities levy land tax (impuesto predial) on real estate property, but the revenues obtained are very low, even in comparison with Mexico's Latin American peers. Revenue from this tax could be raised by ensuring that the municipalities participate in state programs to update their property records, and raising rates with a sufficiently high exemption threshold, to make it possible to implement a progressive scheme, which is important in a country with high levels of inequality. The same is true with water, which is in the municipal domain and displays huge variety in rates, since in some cases water is not charged for while in others, unfortunately the exception, charges succeed in covering costs. 


\section{Strengthening international tax cooperation}

Mexico is geographically close to several tax havens that offer opportunities for Mexican taxpayers to evade taxes. The recent OECD and G20 initiatives offer the government an opportunity to counter such offshore noncompliance. Mexico has already started to exploit these opportunities by negotiating Tax Information Exchange Agreements (TIEAs) and tax treaties that provide for full exchange of information among countries. The next steps involve launching an offshore fiscal compliance initiative along the lines of those established by the UK, US and other OECD countries, increase the resources of the competent authorities in the SAT (the national tax authority), develop programmes to train auditors on how to take advantage of this more cooperative environment, and explore the possibility of establishing automatic exchange of information with other countries.

\section{Key OECD recommendations}

- Increase tax revenues by concentrating on broadening the VAT, personal income and corporate income tax bases and further strengthening the tax administration.

Increase taxes on real estate property and greenhouse gas emissions.

- Strengthen international tax cooperation and eliminate the use of tax havens by Mexican taxpayers.

- Increase fiscal responsibilities of states and municipalities by limiting federal government transfers and allowing higher marginal revenue retention. In the case of the municipalities, the land tax and water rates offer major opportunities to increase revenues. 


\section{The Efficiency of Public Administration}

Over the past few years, Mexico has introduced a wide range of reforms aimed at making the public administration more efficient and increasing the impact of policies. These reforms have included increased fiscal responsibility and transparency in budgeting; better public procurement mechanisms; improved human resource management; and measures to avoid corruption. Although many of these reforms are in place, strong and consistent political support is needed for the legislation to gain traction and generate real savings and productivity gains.

\section{Further improving the budget process}

To achieve sustainable public finances in the long term, Mexico needs a budget that is less dependent on oil revenues and more responsive to long-term sustainable economic growth (see chapter 4). Moreover, the efficiency and effectiveness of public expenditure and the accountability of spending at the sub-national level need to be strengthened. The country needs to develop a longer-term, multi-year, budget approach that aligns spending and funding with the government's plans and goals for different sectors, and prepare better for eventualities such as declining oil revenues and changing demographics.

Further progress is also needed to better link budgeting decisions to performance. This requires stronger incentives and regulatory structures that make the rationalisation of resources easier and budgetary execution and management more flexible. Congress should be increasingly involved in this process, and its members should be encouraged to make more use of outcome data and evaluations presented by the executive branch, both to monitor the performance of important ministries and agencies, and for the purposes of budgetary debate. In its budgeting process Congress can draw on: (i) the Supreme Audit Department of the Federation (Auditoría Superior de la Federación, ASF), which audits public accounts and makes special presentations to Congress on audit processes (also available for public scrutiny on the Internet); and (ii) the Centre for Public Finance Studies (Centro de Estudios de las Finanzas Públicas, CEFP), created by Congress in 1988, ahead of many OECD countries, to provide objective and non-partisan analyses on public finance issues. This is in line with the general trend in OECD countries toward strengthening the budgeting capacities of national legislatures. Another useful measure would be to discontinue the earmarking of spending for specific expenditure (sometimes linked to constituencies, in particular) in the parliamentary discussion of the budget, focusing the attention of legislators into the key objectives of sustainability, fairness and efficiency.

\section{Improving public sector efficiency}

The Mexican public sector needs to significantly strengthen its human resource management, both to improve policy making and to ensure more efficient, effective and competitive provision of services. Public sector human 

Figure 5.1. Life expectancy at birth and health spending per capita, 2009 (or latest year available)

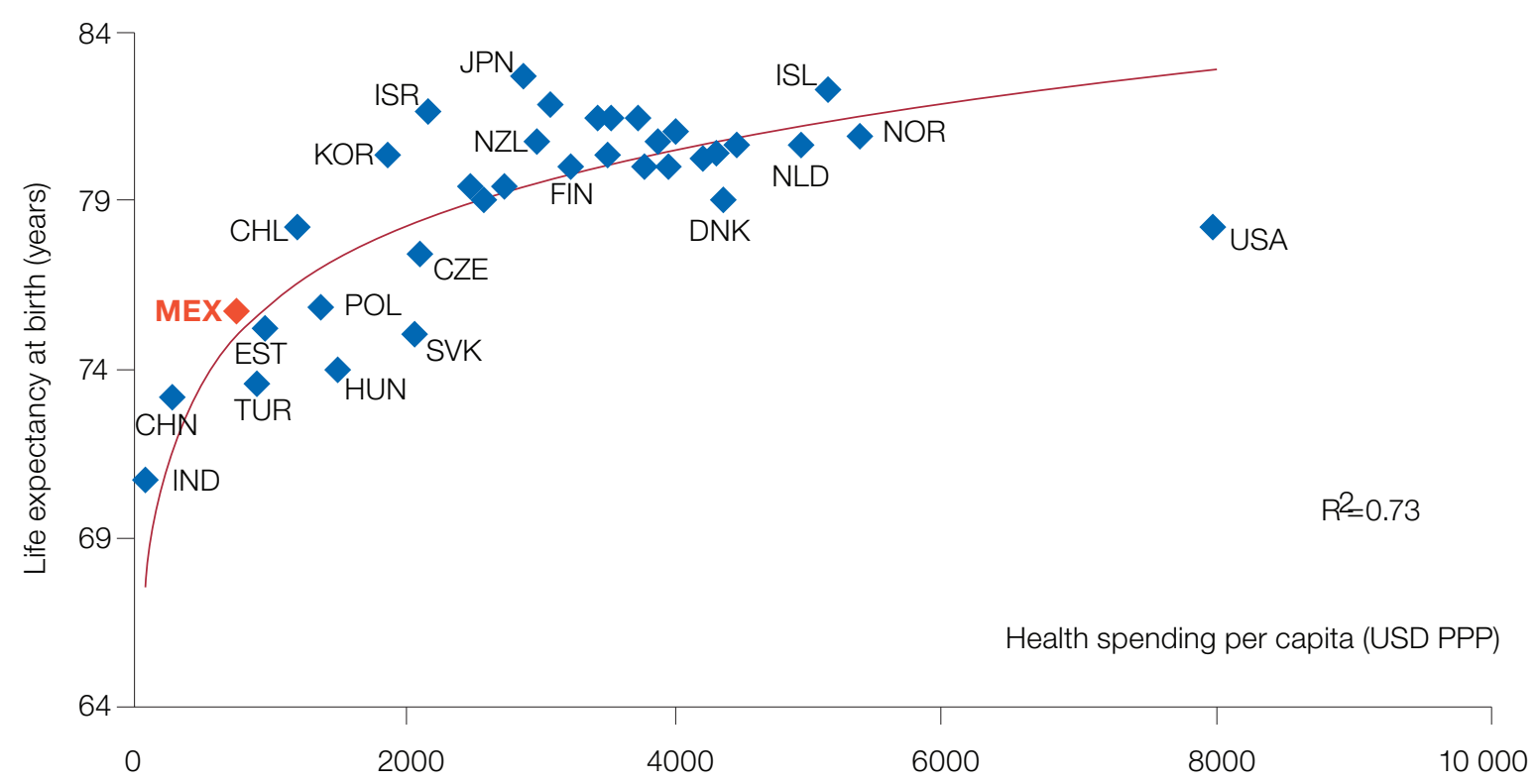

In some cases, the e-government service should be locally grounded and clearly driven by local needs and preferences. In others, there might be a case for more shared services to avoid duplication and ensure that the level of service provided through ICTs is consistently high across the country.

\section{Improving risk management}

The benefits of coordination across public policies and among government bodies are illustrated by the issue of risk management. Given the perception of increasing frequency and severity of natural and man-made shocks, OECD countries are emphasizing risk preparedness and putting more integrated systems in place to ensure an effective response to events when they occur. These integrated systems recognize the need for coherent action not only by security and emergency services but many other line ministries, including strong leadership from the centre and effective coordination between the central government and local levels. The OECD is working with the Mexican Civil Protection service to review the country's risk management systems and mechanisms.

\section{Key OECD recommendations}

- Design a multi-year budgeting process, with a focus on expenditure performance and effectiveness, and on outcomes in the public sector.

- Improve government efficiency by professionalizing the civil service, taking steps to enhance expenditure quality, and expanding transparency and open government initiatives. 
- Ensure more strategic spending through better procurement, supported by planning, collection of data for assessment and a specialised workforce within each public organization.

- Measure citizen satisfaction with ongoing e-government tools to promote open government in order to better align supply with demand, and explore options for developing shared services across different levels of government. 


\section{Regional Disparities}

Mexico is one of the OECD countries with the highest levels of income inequality, not only among individuals but also between regions. Inter-regional disparities have even widened in the last 20 years as the benefits from trade liberalisation have been captured better by some regions than by others (Figure 6.1). Policies to address territorial inequality in Mexico have largely been compensatory rather than focused on mobilising the growth potential of lagging states. As the persistent poor performance in some states reduces aggregate growth, Mexico's national development strategy should instead foster states' competitiveness and look for potential complementarities between policies with a view to increasing efficiency and growth and those that address inequality.

\section{Fostering states' competitiveness and productivity}

Mexico's states not only have lower GDP per capita than the OECD average, but most of them are underperforming in terms of growth. In the past decade, only eight of the 32 Mexican states grew faster than the OECD average. This poor performance is largely due to low productivity growth, compounded by insufficient investment and employment at the regional level. Evidence from OECD regional growth modelling suggests that regions need not only to work on having infrastructure in place and on building human capital assets, but also to create business environments that favour entrepreneurship and innovation. Mexico's policies on these fronts are fragmented among several ministries, with no single "gatekeeper" for regional policy. There is a need to revise the multi-level governance framework in Mexico, with a view to clearly defining the roles that each actor has in promoting regional growth, with the aim of boosting national development.

\section{Strengthening fiscal federalism}

Fiscal federalism reforms could provide better incentives for states and municipalities, and also promote policy coordination across the different levels of government. During the 1990s Mexico started a process of decentralisation of core expenditure responsibilities to the states, and to a lesser extent, the municipalities. Two decades later, the decentralisation process is halfway through. States have formal responsibilities over major spending categories, including such key areas as health and education, and they account for almost half of all public expenditure. However, the devolution of expenditure responsibilities has not been mirrored on the revenue side: states and municipalities remain highly dependent on federal transfers. This reduces incentives for efficient spending and prudent fiscal management at the sub-national level. Expenditure responsibilities across levels of government are poorly defined and often overlap, reducing the efficiency of public spending. Information on the use of sub-national governments' financial resources is scant and there is no homogeneous and standard reporting of sub-national budgets, despite the fact that the law mandates that all levels of 
Figure 6.1. Regional disparities across OECD countries

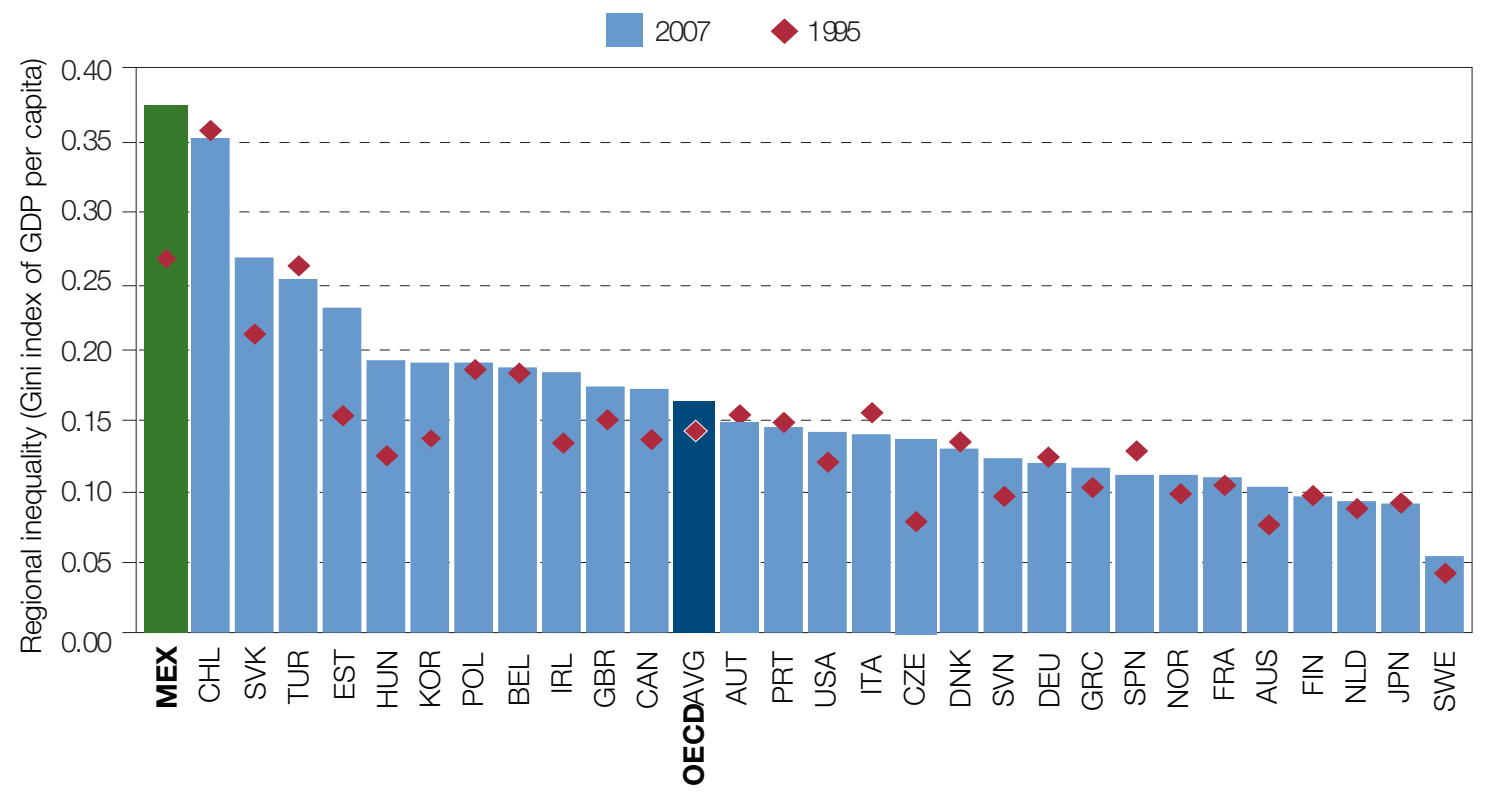

Source: OECD Regions at a Glance (OECD, 2011).

government should adopt a results-based budgeting framework. This reduces transparency and makes fiscal performance more difficult to evaluate.

On the revenue side, sub-national governments' own revenue shares are extremely low by international standards. Payroll taxes account for the largest part of states' own revenues. Although easy to collect, they have the disadvantage of increasing the cost of labour in the formal sector. For municipalities, the most important revenue source is the property tax - a comparatively more efficient form of taxation - but revenues are exceptionally low even in comparison to Latin American peers. This is due to outdated land registers, which lead to undervaluation of property, as well as weak incentives to collect higher property taxes. Mayors in Mexico can only run for a single three-year term and this is insufficient to reap the benefits of taking the unpopular step to raise property taxes. A first step to strengthen property taxes is for municipalities to engage in state programmes to update land registries, for which the states could hire and train the personnel and provide the infrastructure needed. Extending the three-year term for mayors, or allowing for re-election, would also help increase incentives to collect taxes.

The federal government has taken steps to increase incentives and capacities for the states and municipalities to collect their own taxes. For example, sub-national borrowing rules had been made more stringent, discontinuing extraordinary transfers to states and providing information on federal investment projects. The formulas for various non-earmarked federal transfers now take account of both the level and increase in subnational government tax collection to reward states' efforts to collect taxes. In 2007, the states were authorised to levy three new taxes: a new tax on gasoline and diesel, a tax on final sales of certain goods subject to IEPS, and transfer of vehicle property tax as from 2012. Nonetheless, these new tax powers have not been taken out by most states. This is possibly due to their limited capacity to collect the taxes, but also to a lack of incentives, since it is easier for the states to lobby for more federal transfers than to intensify their own revenue collection efforts. Future increases in federal transfers should be limited so that states have more incentives to raise more of their own revenue. Conferring taxing powers for broader tax bases to the states, such as surcharges on 
Figure 6.2. Sub-national government revenue and expenditure, $2010^{1}$

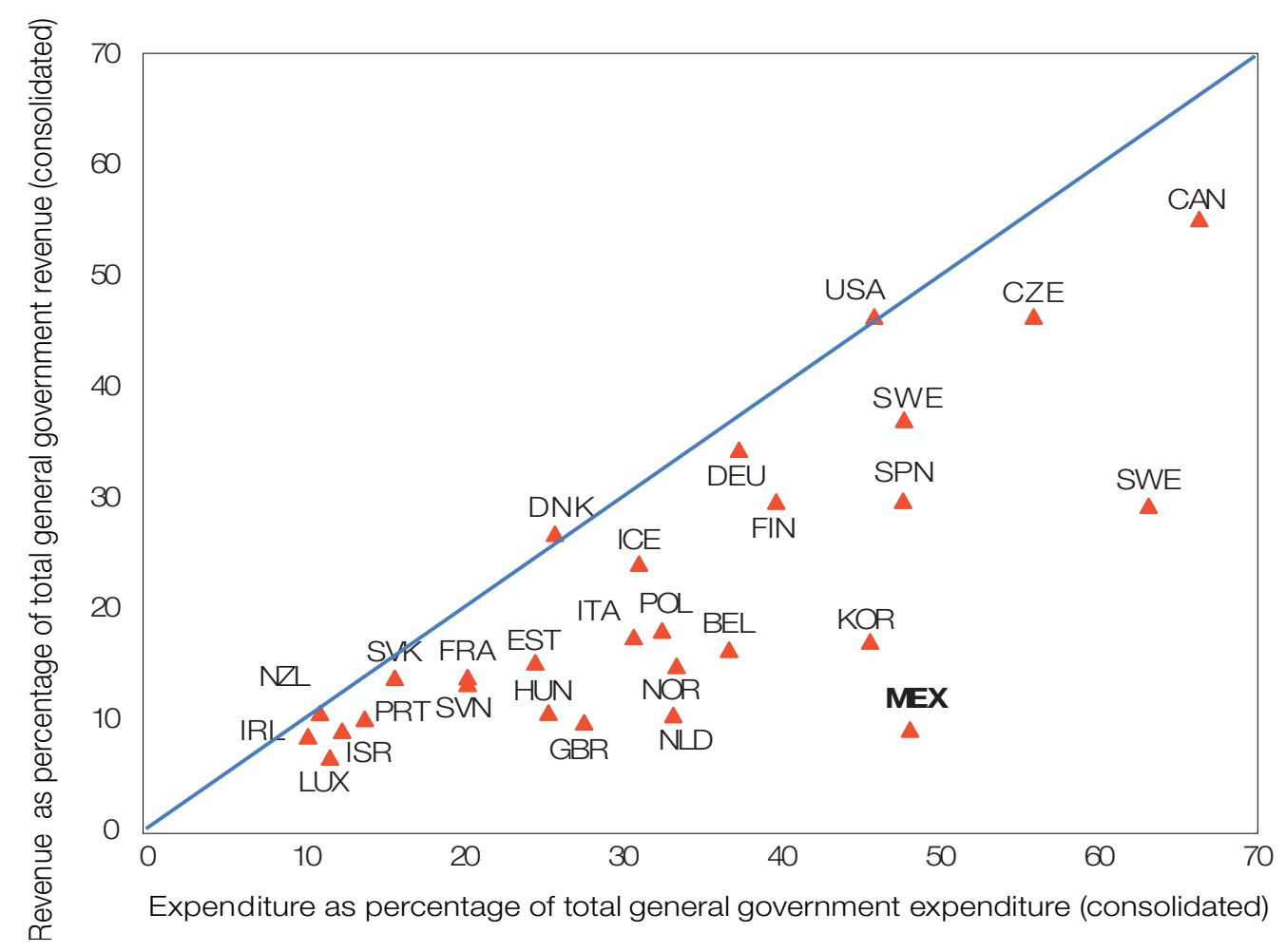

1. 2009 for Mexico, Korea and New Zealand.

Source: OECD Fiscal Decentralisation Database.

income taxes or VAT, should then meet with more success. This should be combined with a well-functioning and transparent fiscal equalisation mechanism, which would make sure that poor states have the necessary resources to strengthen their growth potential and promote catch-up (Figure 6.2).

\section{Improve local government capacity to charge for water services}

A clear example of the challenges facing the states and municipalities in providing core utilities are water rates. In Mexico, water rates vary considerably between municipalities and states, but are generally lower than needed to recover operating and maintenance costs. Consequently, service operating agencies basically depend on government subsidies to cover their investment needs. This income structure makes it difficult to increase commercial sources for investment in the sector.

As in the case of other local incomes, the authorities do not have incentives to raise rates to a sustainable level. The short term of office of municipal authorities makes it politically difficult to raise rates. In addition, federal subsidies are generally not linked to the performance of service providing agencies, thereby further reducing incentives to make difficult decisions on rates, and generally improve the efficiency and quality of the service. The methodology developed by the National Water Commission for setting rates for drinking water and drainage services, as a voluntary tool to promote a more consistent approach, is a step in the right direction. Nonetheless, as it is not compulsory, there are no incentives for local authorities to adopt it, as evidenced by the low adoption rate thus far. It should be noted, however, that some states (including Nuevo León, Baja 
California and Sonora) have accumulated significant experience in setting rates, which could be useful for other states. This topic is considered in greater detail in chapter 20.

\section{Key OECD recommendations}

- Create a single federal gatekeeper for regional policy in charge of policy design, provision of incentives for sub-national action, and horizontal coordination of stakeholders.

- Unify funding for regional development policies and increase certainty through multiyear budgeting arrangements. Clarify expenditure responsibilities across levels of government and eliminate overlaps or duplicities.

- Establish a common budget classification and accounting framework consistent with international standards at all levels of government.

- Strengthen monitoring and evaluation by extending ex-post evaluations beyond social programmes to other policy areas, states and municipalities.

- Improve states' incentives and tax revenues, by limiting federal transfers and granting more tax powers to states.

- Improve the transparency of federal transfers to state and municipal governments and enhance their fiscal equalisation properties.

Keep taxable property registry values up-to-date to increase land tax revenues.

- Promote and support the sustainable financing of water services via higher local revenues, better understanding of the constraints of water availability, and an increasing social perception of its price increase

- Foster state congresses' focus on supporting consistent measures with water-setting rates, and increase the capacity of service operating agencies so they can reach financial sustainability, 


\section{The Labour Market}

A properly functioning labour market is crucial for economic and social performance, and hence poverty reduction. The Mexican labour market has performed better than that of most OECD countries in the recent past. Total employment grew by $3.8 \%$ in the year to March 2012 - the second largest increase in the OECD after Turkey. Although unemployment remains above its pre-crisis level (5.0\% in the first quarter of 2012), it is well below the OECD average of $8.2 \%$. Going forward, the latest OECD Projections (June 2012) suggest that the unemployment rate is expected to stay above its pre-crisis level for some time to come, especially in light of the recent weakening of the economic recovery in the OECD area. Nevertheless, for the labour market to contribute more effectively to higher living standards and inclusive growth, major reforms are needed to promote formal employment (Figure 7.1).

\section{Figure 7.1. Recent trend of the harmonized unemployment rate in Mexico and the OECD area}

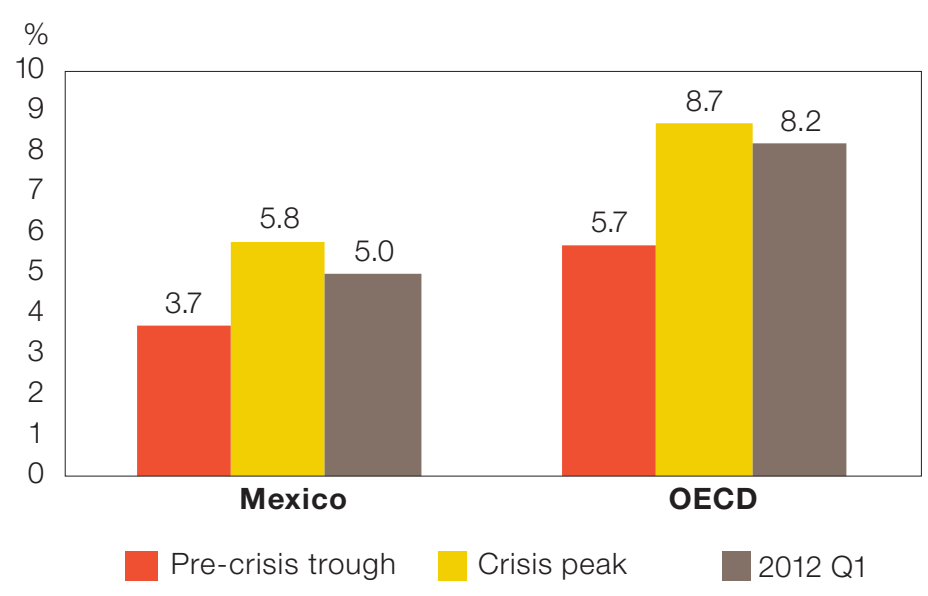

Source: OECD Main Economic Indicators Database.

\section{Informal employment remains an issue}

Since the crisis, informal employment has increased substantially from its already high level, and by more than during previous recessions. In the initial phase of the crisis, this was caused by a reduction in formal employment due to faltering export demand. Subsequently, the increase in informal employment largely reflected, above all, the incorporation of formal sector workers who had lost their jobs, along with unemployed 
looking to make up for the loss of household incomes. In the second half of 2011, formal employment recovered somewhat, but it is still far from having regained its pre-crisis level.

\section{Figure 7.2. Trend of the share of selected groups of the working age population in formal employment, 2008-2011}

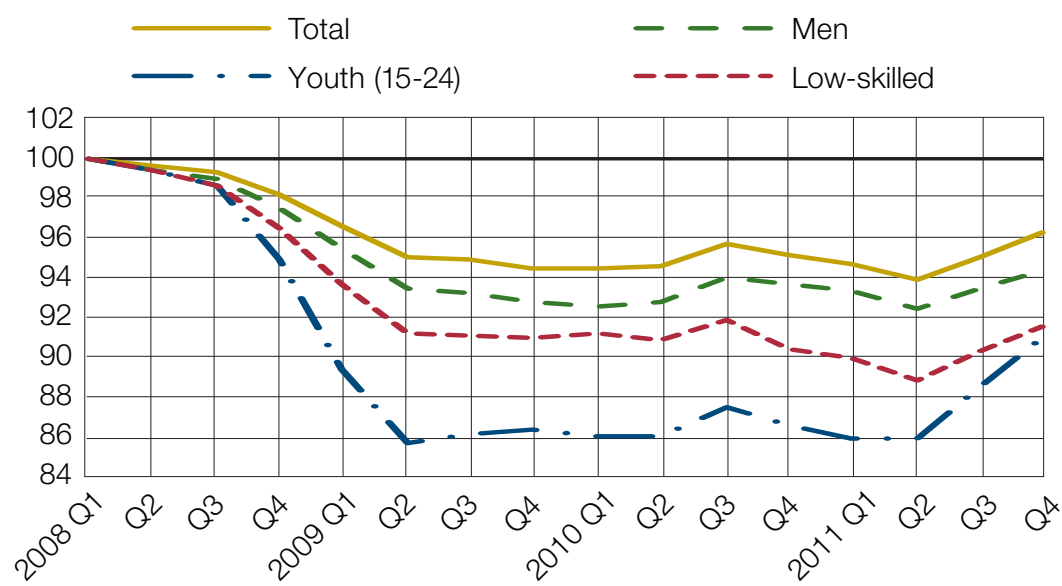

Quarterly data smoothed using 3-quarter moving averages with base 100 at the peak date (Q1 2008). Formal employment includes workers affiliated to Social Security (IMSS/ISSSTE) through their job.

Source: OECD calculations based on the National Employment and Occupation Survey (Encuesta Nacional de Empleo y Ocupación, ENOE).

Youth and low-skilled workers, mostly men, were hit particularly hard by the decline in formal employment, compared to other groups in the working-age population (Figure 7.2). Although formal employment shrank by about $5 \%$ overall, the reduction was two or even three times steeper for unskilled workers and youth. This pattern, which is common to many OECD countries, reflects the relative vulnerability of formal-sector workers who have little work experience, low skill levels, and fixed-term contracts with little or no social protection, which implies relatively low hiring and firing costs. Youth and the low skilled are also the groups that benefited most from the recent upturn in formal employment.

\section{Reducing informal employment with better social protection policies}

The growth of informality reveals the limited scope of income-support measures available to workers losing their jobs. Mexico is the only OECD country without a system of unemployment benefits. Although, in principle, formal sector job-losers with individual pension accounts can draw on their savings, in practice, the conditions for doing so are very restrictive. The creation of an effective unemployment insurance scheme ought to be a fundamental priority of labour market policy. This could take the form of an individual savings account system combined with a public component for job losers who have insufficient savings, as in Chile. The existing system of individual pension accounts could provide a useful starting point. Unemployment insurance has fiscal costs however, which makes fiscal reform both essential and urgent.

Other measures could discourage working in the informal sector. For example, health service coverage has grown sharply during the past decade thanks to the establishment of Seguro Popular, a new non-contributory 
health system (see chapter 9 of this report). Data published in the OECD's 2011 Employment Outlook show that the introduction of non-contributory programs alongside contributory ones has not necessarily increased incentives for informal work (by reducing the relative benefits of the current contributory system). Even so, better integration of the various health systems, as well as making the Seguro Popular dependent on each individual's income, would be useful measures to prevent the creation of incentives to work informally.

\section{Reforming labour law}

Apart from strengthening safety nets for formal workers, a reform of labour legislation could help promote formal employment and boost productivity growth. Although current provisions governing the hiring and firing of permanent workers and the use of temporary contracts are highly restrictive, they are poorly enforced. Easing these provisions and ensuring compliance, while at the same time strengthening safety nets for formal workers would provide incentives to formalise jobs and thus overcome labour market segmentation.

A labour Law Reform Bill is currently in Congress, which, although perfectible, could serve as a basis for achieving this important aim within a relatively short time.

\section{Key OECD recommendations}

- Increase incentives for formal activity by integrating the various health schemes more effectively and making the subsidy component of Seguro Popular dependent on income. Expand social security coverage and access to services in areas such as housing and child care.

- Strengthen measures to ensure tax and social security compliance, as part of a comprehensive strategy to encourage informal workers to register their activity.

- Simplify the tax system, which does not provide incentives for hiring unskilled workers. The government could also consider making social security contributions compulsory for selfemployed workers, especially those with incomes above a certain level.

- Promote short-term and part-time work contracts as a means to encourage women's participation in the labour market, while ensuring thair guarantees and protection.

- Introduce new types of training arrangements, such as apprenticeship contracts.

- Encourage recourse to probation periods, provided that these are designed to make it easier to turn temporary hirings into longer-term job contracts and prevent abuse.

- Implement a comprehensive and balanced labour reform which should include: reducing the cost of hiring and firing workers (especially those with short tenure); facilitating the use of temporary contracts while improving enforcement of employment protection legislation; improving trade union freedom and the representation of workers in collective bargaining; and creating an effective unemployment scheme for workers. 
Figure 8.1. Mexico's Mean Scores in PISA, Annualised Trends and Enrolment of 15-year-olds

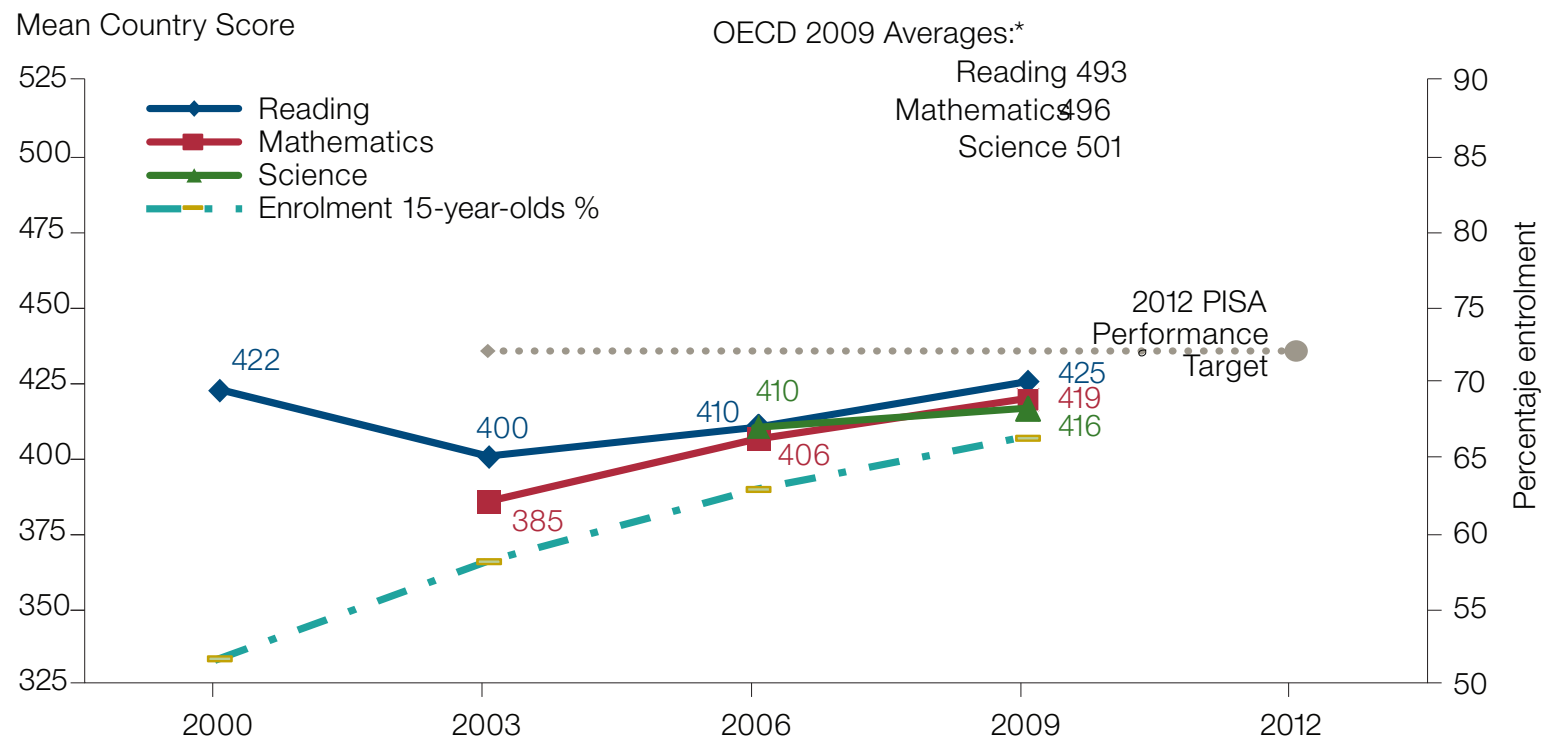

PISA Assessment Years

Note: The 392 score-point baseline corresponds to the simple rounded average of Mexico's country mean scores in PISA for 2003 in reading (399.72) and mathematics (385.22). For this reason, the average of scores for reading and mathematics are referred to in this section.

*Every 40 points of difference is equivalent to one year of education.

standards, to clarify to all those engaged in the education process what knowledge they need to deliver and what constitutes effective teaching and learning. To consolidate these improvements, Mexico has also developed a universal evaluation system for basic education, looking for increased accountability. In addition to teacher and school leadership evaluation, it includes the enhancement of national evaluation based on outcomes. The strengthening of the ENLACE assessment, and its alignment to the new curricular standards can provide the targets needed for planning and measuring progress, provided they include equity and quality criteria (Figure 8.2).

\section{Strengthening vocational education and training (VET) and tertiary education}

The Mexican VET system has many strengths, including opportunities for learning in remote areas, measures to support students at risk of dropping out and effective collaboration between businesses and local vocational schools. To further strengthen the system, Mexico needs first a formal consultation framework between employers, unions and the VET system. Second, quality standards and trainee contracts should be introduced to expand workplace training as an integral part of vocational programmes. Third, VET teachers should receive pedagogical training either before they become teachers or immediately afterwards. Fourth, Mexico could explore options for a national qualifications certification framework; and, fifth, the capacity to analyse and use data on labour market needs has to be developed to guide future policy design and improve decision-making. 
Figure 8.2. Percentage of teachers whose school principal reported that the indicated teacher characteristics hinder instruction in their school (2007-08)

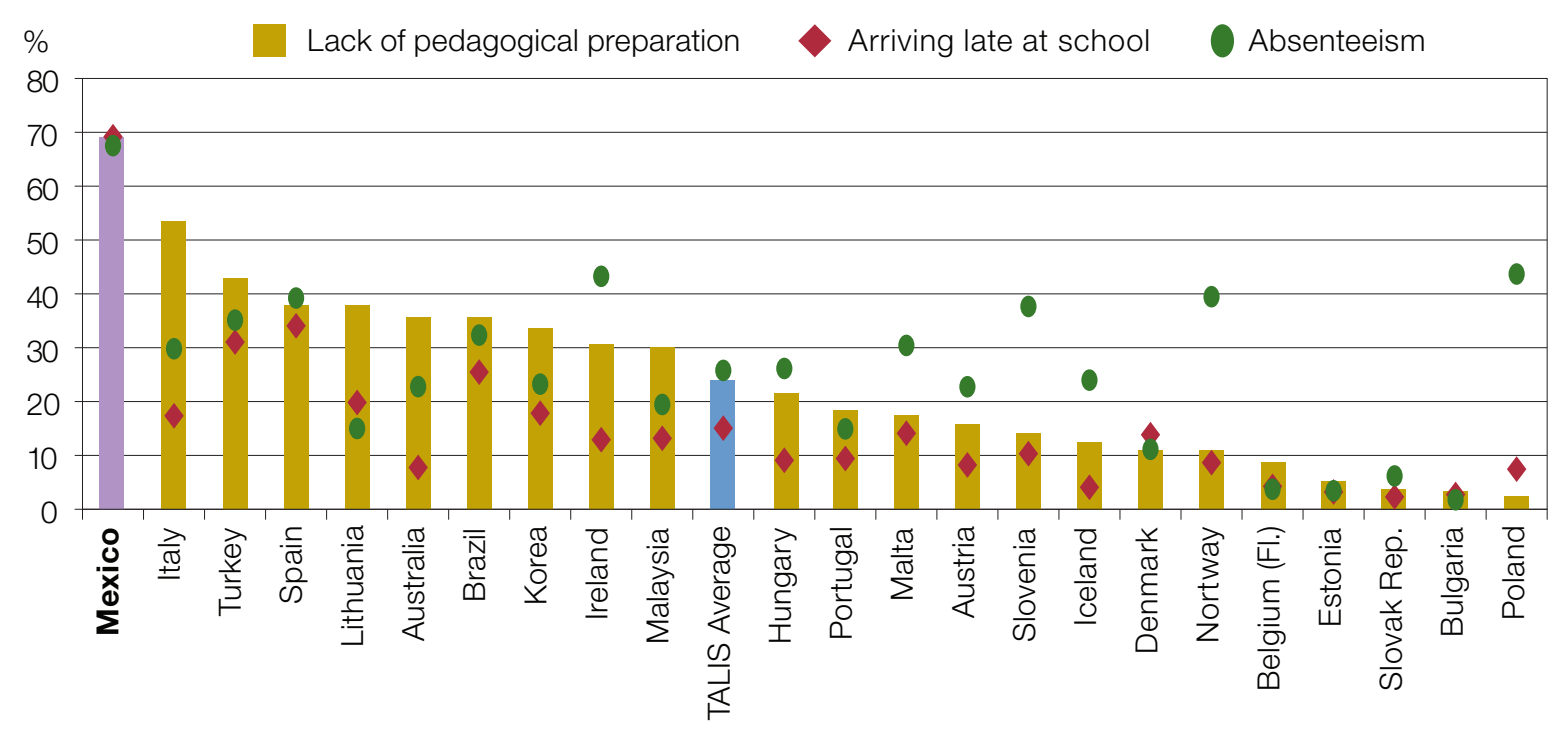

Countries are ranked in descending order of the percentage of teachers citing a lack of pedagogical support as an obstacle to their teaching.

Source: OECD (2008), Creating effective teaching and learning environments: First results from TALIS, OECD, Paris.

Although Mexico has been working to expand the coverage and equity of tertiary education, significant challenges persist. Only 20\% of 25-34 year-olds in Mexico attend tertiary education, compared to $37 \%$ across OECD countries. Between 1995 and 2008, expenditure in higher education increased by 78\% but, because the number of students increased quickly, expenditure per student only increased by $16 \%$. A reform of tertiary education funding should include: an assessment of the sustainability of the current cost distribution (tuition fees vs subsidy) and whether it adequately reflects the relative magnitude of the benefits that tertiary education provides to society; improvement of the transparency with which funds are allocated to institutions; and a significant expansion of the support system for the most needy students.

\section{Key OECD recommendations}

- Continue to expand ECEC coverage while improving its quality through staff capacity building and pedagogical improvements.

- Strengthen investment in teacher effectiveness, especially through teacher initial and continuous in-service training, revise processes for assigning teachers to schools and raise awareness of teaching as a profession. This should be accompanied by a well designed and implemented teacher appraisal system.

- Make better use of student performance data, but also of the information available on national curricular, teaching and school management standards not just to evaluate schools but also to secure improvement where needed. 
- Strengthen the vocational education and training (VET) system by forging closer collaboration between employers and unions, integrated workplace training, higher teaching quality, and better data. Also explore options for a national qualifications certification system.

- Reform tertiary education funding, seeking a balance between public cost and social benefit (tuition fees vs. subsidy), improving the transparency of resource allocation to institutions and enhancing mechanisms that support most needy students and promote equality. 
Figure 9.1. Health expenditure as a share of GDP (2009 or nearest available year)

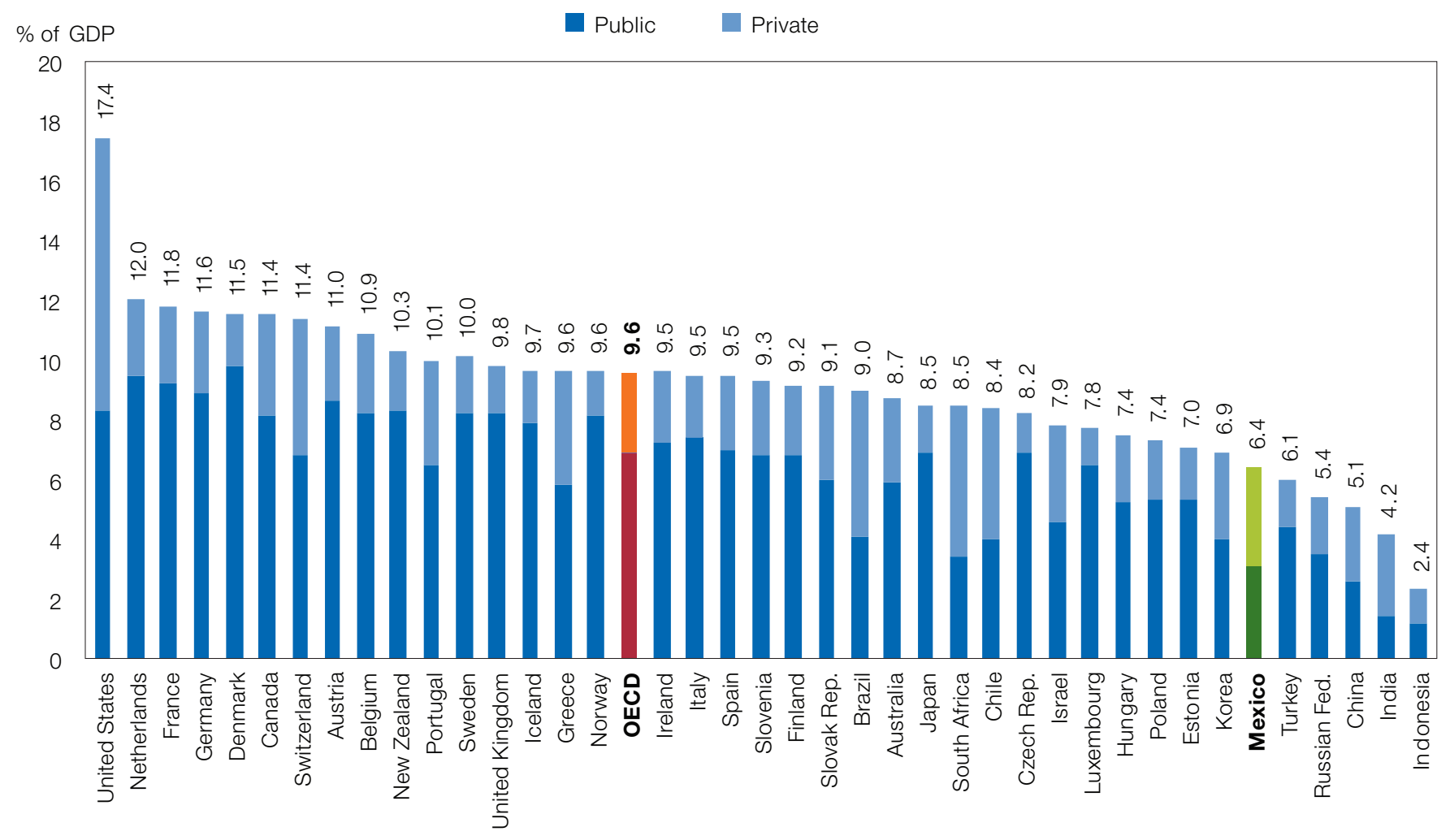

Source: OECD Health Data 2011; WHO Global health expenditure database.

\section{Improving quality and effectiveness of health care}

Poor-quality health care stems partly from an insufficient number of doctors and hospital beds. Despite a large increase in supply since 1990, Mexico had two doctors per 1000 people in 2009 compared to an OECD average of 3.1, while the ratio of hospital beds was approximately a third of the OECD average.

In the poorest states the difficulties are compounded by the fact that public financing per capita continues to be inversely proportional to indicators of poverty, such as infant mortality, and therefore "freezes" the disadvantage of the poorest geographical areas. Reducing differences in the quality of health care across the country will require targeting limited resources more precisely on where they are most needed.

\section{Overcoming emerging health threats: obesity and diabetes}

Mexico is the second most obese country in the OECD after the United States. Rates have risen from $24 \%$ in 1990 to $30 \%$ of the adult population in 2008. Nearly one in three children is overweight or obese. Diabetes, the chronic disease most directly linked with obesity, now affects an estimated 10.8\% of the population aged 
20-79 years, the highest rate in the OECD. Recent health promotion efforts through local initiatives and further measures at the school level are welcome developments, but more can be done. OECD analysis shows that a package of effective measures, including health education and promotion of a healthy lifestyle, regulation of food advertising to children, introduction of fiscal measures involving a combination of quality-based food taxes and subsidies together with lifestyle counselling by family doctors, could be implemented for an annual cost of USD 12 per person in Mexico.

\section{Key OECD recommendations}

- Ensure adequate funding of the health system by introducing the necessary fiscal reforms.

- Reduce remaining barriers to access to services by improving service availability and quality and by progressively expanding the health care package covered by the Seguro Popular.

- Encourage greater efficiency in public hospitals by introducing a clearer purchaser-provider split and output-based payment mechanisms among institutions.

- Encourage greater productivity of health-care professionals by linking remuneration to efficiency and quality, ensuring that private practice by doctors does not reduce the availability of public services.

- Improve systemic governance by strengthening information mechanisms and accountability frameworks for all institutions and by investing in managerial capacity at all levels of the system.

- Promote quality and cost-effectiveness of care by furthering illness prevention and health promotion initiatives, especially to address the growth in obesity and diabetes. 


\section{Gender Equality}

As in most OECD countries, in Mexico gender gaps in education have been closing and have even reversed. Despite major progress in education, however, gender gaps in terms of paid and unpaid work are among the largest in the OECD. Currently there is universal enrolment in primary education without gender differences. At the secondary and higher education levels, girls have higher enrolment rates than boys ( $90 \%$ compared to $84 \%$ ) and higher graduation rates (21\% and $18 \%$, respectively). In terms of academic performance, Mexican girls achieve similar or even better performance than boys. At 15 years of age, girls are ahead of boys in reading. In mathematics and science, boys do better than girls, but the differences are small (Figure 10.1).

Stereotyped attitudes on academic issues have a major effect on gender differences in academic performance and in the choice of professions. Several OECD countries deploy practices to break with traditional stereotypes (Germany), increase girls' interest in science and mathematics (Korea) and encourage girls to study science,

Figure 10.1. Enrolment rates in secondary education by gender, 2010

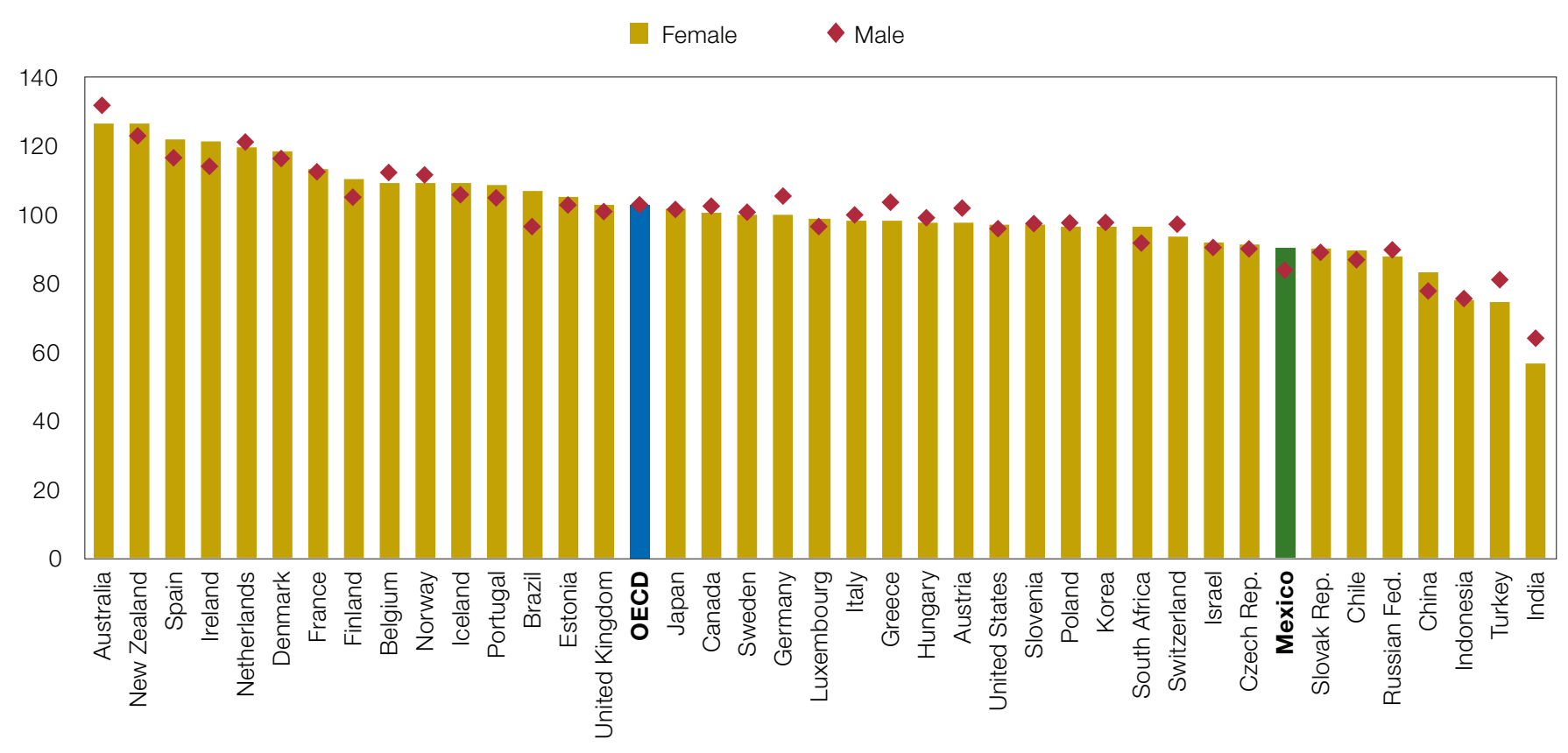

Note: The gross secondary school enrolment rate measures the total number of students enrolled at the secondary level, irrespective of age, as a percentage of the population theoretically of secondary school age. The rate may be higher than $100 \%$ as a result of grade repetition or entry at younger or older ages than the typical age for that education level.

Source: OECD Gender data browser. 
engineering and construction careers (Carrefour de métiers, France, and the UK-Wise campaign, United Kingdom).

Women's employment rates, despite having risen moderately, are the lowest in the OECD after Turkey (43\% of Mexican women have a paid job, compared to the OECD average of $60 \%$ ). The modest participation by Mexican women in the labour market is largely due to the lack of policies to reconcile work and family life, particularly the inadequate supply of childcare services (crèches). Efforts to increase the coverage of childcare (Programa de Estancias Infantiles para Apoyar a Madres Trabajadoras - PEIMT) and preschool services (enforcing the compulsory nature of preschool education) are initiatives that point in the right direction, but more could be done. Examples of successful programs in this area include Chile's "Chile Crece Contigo" and "Sure Start" in the United Kingdom; both of these programmes have helped increase employment among women facing difficult access to the labour market, and they have placed special emphasis on the quality of services (Figure 10.2).

Informal employment is highly prevalent in Mexico (see chapter 7): over half of all Mexican women with a job work in the informal non-agricultural sector. Through the PEIMT and Seguro Popular (see chapter 9), Mexico has made significant progress in expanding social protection services in health to the most vulnerable groups, including informal workers. Seguro Popular also has a specific component for women: the Healthy Pregnancy Strategy, which provides free healthcare before, during, and after childbirth to affiliated women. In addition, a large number of informal female workers are in domestic service, which means they generally face deplorable employment conditions. A useful example of practices to improve the working conditions of such workers is the legislation introduced in 2002 in South Africa (Domestic Workers Act).

Figure 10.2. Labour market participation rates by gender, 2010

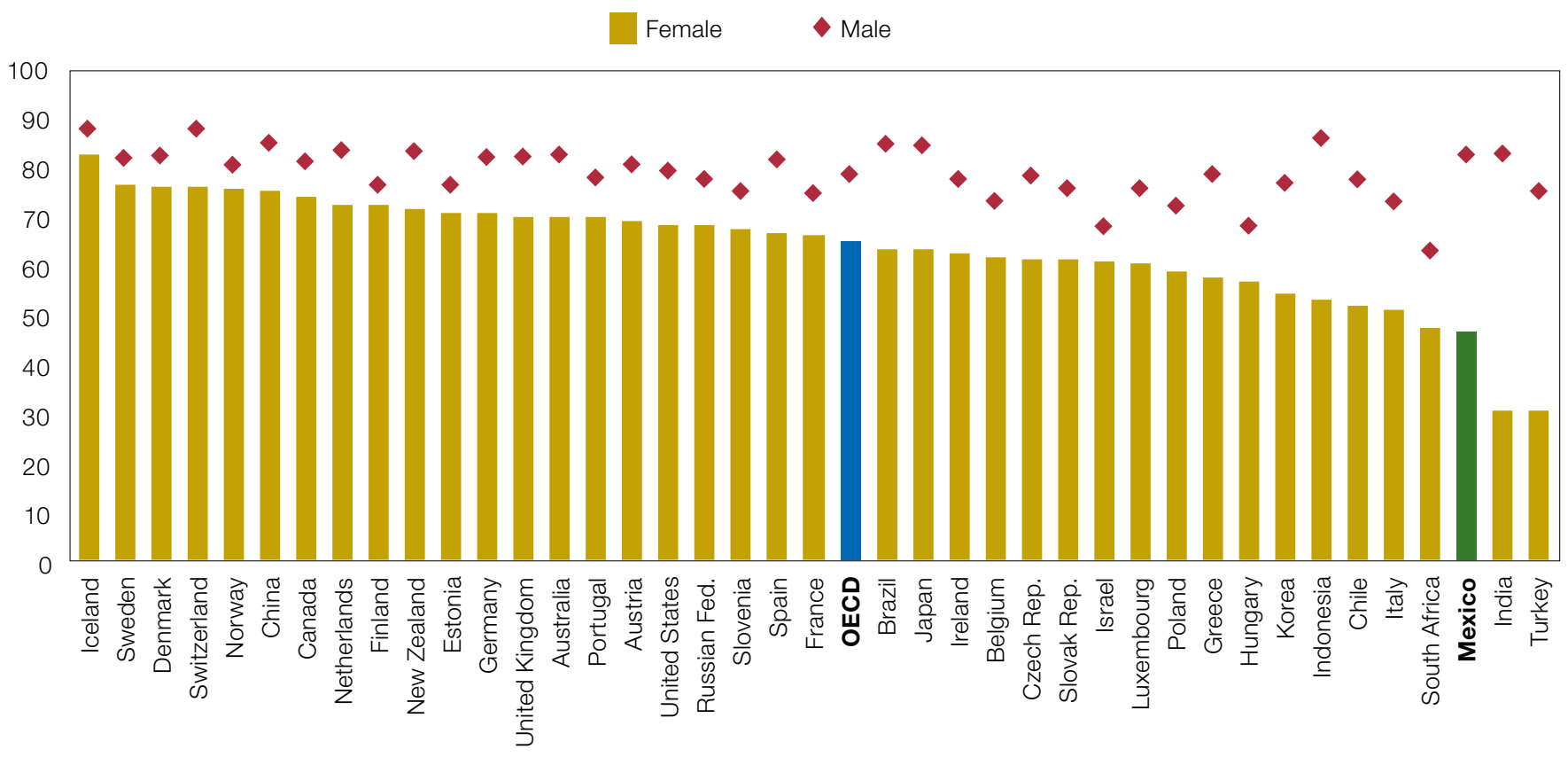

Source: OECD Gender data browser. 
Parental leave, and leave for other family reasons, can help reduce gender gaps in paid and unpaid work. Nonetheless, this type of leave is scarce in Mexico. Maternity leave, although paid at the rate of $100 \%$ of the most recent wage, lasts 12 weeks in all and only covers women in formal employment. There is no other form of parental leave that includes fathers. Countries such as Chile and Brazil give five days' paternity leave. In addition, there is little access to other types of policies to reconcile work and family life, and facilitate women's employment, such as flexible working arrangements.

Mexican women are under-represented in management posts, earn less than men, and are less likely to have a business and employ other workers: just $7 \%$ of the members of the boards of Mexican firms are women ( $10 \%$ in the OECD), and only $2 \%$ of Mexican women are entrepreneurs (similar to the OECD average). There is no information for Mexico on wage gaps.

Gender gaps are also present in unpaid work in Mexico. Mexican women spend four hours a day more than men in unpaid work in the home - double the OECD average. Domestic chores have a negative effect on the number of hours worked by women and on the wage gap. Gender roles are a major barrier to economic opportunities in Mexico and for Mexican women.

\section{Key OECD recommendations}

- Promote a culture of gender equality from childhood through didactic literature, playing activities, school workshops, and other types of activities that make it possible to change stereotyped attitudes towards gender roles.

- Strengthening public support and develop policies to reconcile work and family life, including paid leave for fathers and flexible working arrangements, are crucial for mobilizing women's employment and improving gender equity.

- Redouble efforts to increase the coverage and improve the quality of early childhood care services (crèches). Accessible, affordable and high-quality services are essential for facilitating women's employment.

- Maintain efforts by institutions such as INEGI and INMUJERES to compile and produce data for monitoring gender gaps. 


\section{Innovation}

Mexico performs very poorly in science and innovation (Figure 11.1). In 2009, gross domestic expenditure on research and development (R\&D) amounted to just $0.44 \%$ of GDP, the lowest rate of all OECD countries (virtually half what is invested by Turkey (0.85\% of GDP) and way below countries such as Korea (3.6\%), Finland (4\%), or Israel (4.3\%). Business R\&D is particularly low. Fostering innovation is essential to boost productivity and create new sources of growth.

Various factors explain the weakness of innovation in Mexico, including a flawed legal framework and shortcoming in the governance of the innovation system. Efforts are underway to overcome these weaknesses. Particular focus areas are the commercialisation of public research and the conditions for innovative entrepreneurship.

\section{Promoting the commercialisation of public research}

Nowadays, there are several new innovation support programmes that include the development of industryscience linkages as primary or secondary criteria for determining the eligibility of projects or selecting projects. New initiatives have recently been taken to promote the development of Technology Transfer Offices (TTOs)

Figure 11.1. Comparative performance of Mexican science and innovation system, 2010

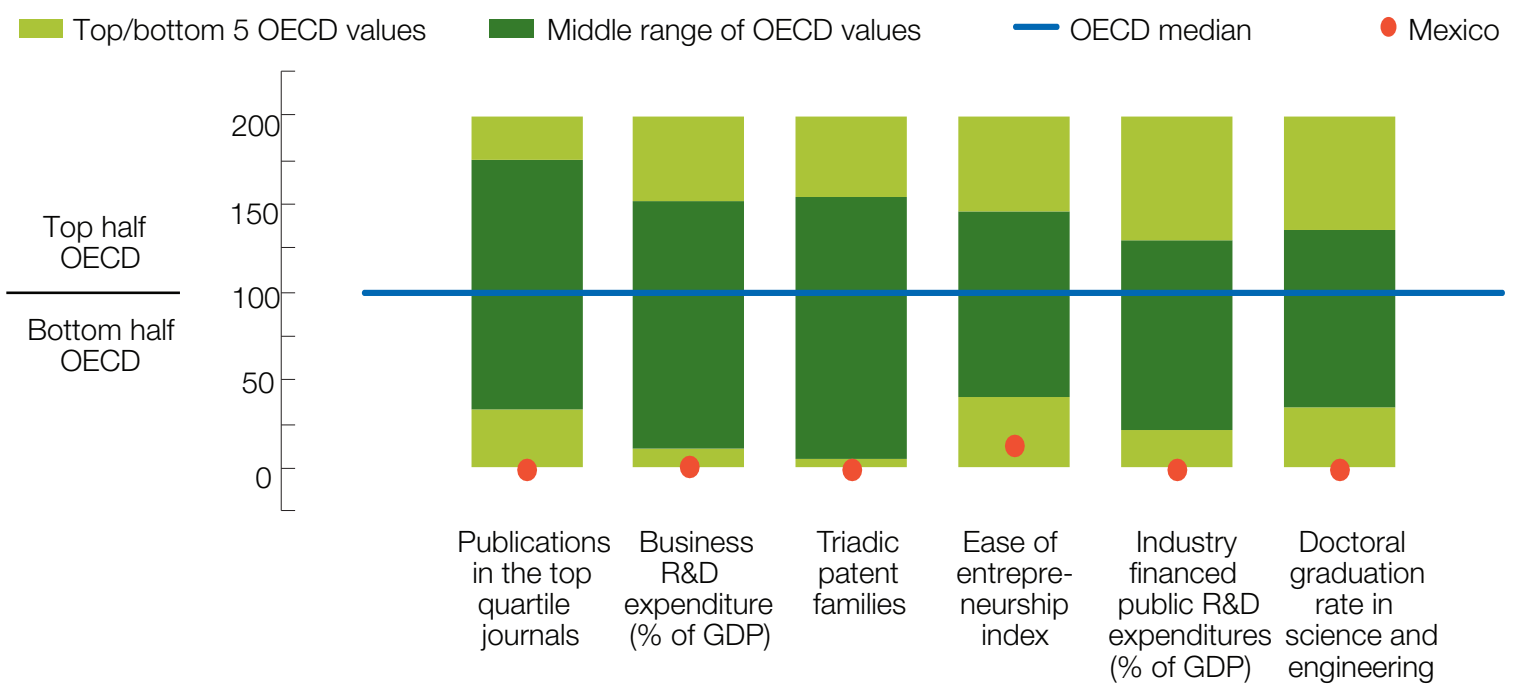


with a view to enhancing the commercial use of research outcomes, facilitating the creation of technological spin-offs promoted and managed by university students and meeting the demand for technological services through an innovation voucher system. This new policy stance should be continued.

\section{Creating the conditions for innovative entrepreneurship}

The innovation policy mix has recently changed. Tax incentives were eliminated in 2009, and the allocation of public funding to the business sector has been made direct and competitive. A new R\&D and innovation stimulus package was introduced in 2009 with a strong emphasis on SMEs and linkages with research institutions. New innovation programmes financed by the Ministry of Economy have also been introduced.

In addition to the necessary improvement of framework conditions (such as improving human capital, promoting entrepreneurship and competition), more should be done in the area of innovative entrepreneurship policy.

\section{Key OECD recommendations}

- Ensure policy continuity: programmes should be stabilised and their focus should change less often.

Eliminate inefficiencies derived from the implementation of certain tax incentives and improve the delivery of support programmes so as to ensure necessary funding over the various stages of innovative projects.

Improve clarity of the public support system for users.

- Consider increasing the currently partial decentralisation of federal support programmes to strengthen the development of local innovation ecosystems involving collaboration between incubators, TTOs, and venture capital associations.

- Consider the creation of tax relief for investors in start-ups, venture capital funds, etc. 


\section{Integrating Mexico into}

\section{the World Economy through Trade and FDI}

Trade and foreign direct investment (FDI) have grown considerably over the last few decades and now account for a large share of Mexican GDP. Trade and FDI are among the main sources of new and better paid jobs, making a significant contribution to the country's economic development. Manufactured exports have been a key component in Mexico's growth performance and participation in world markets. Manufactured products, particularly automobiles, tow-trucks, radio, television and communications equipment and apparatus make up some three-quarters of Mexico's merchandise exports. Since the mid-1990s, Mexico's share of world merchandise exports has outweighed its contribution to world GDP.

\section{Opening the service sector and attracting FDI}

In contrast to the country's dynamic participation in merchandise trade, Mexico's share of OECD trade in services remains below potential and has been shrinking since 2000 (Figure 12.1). This trend coincides with a declining contribution of services to GDP, from 68\% in 2001 to $61 \%$ in 2010; this is currently 12 percentage

Figure 12.1. Mexico's share in OECD trade

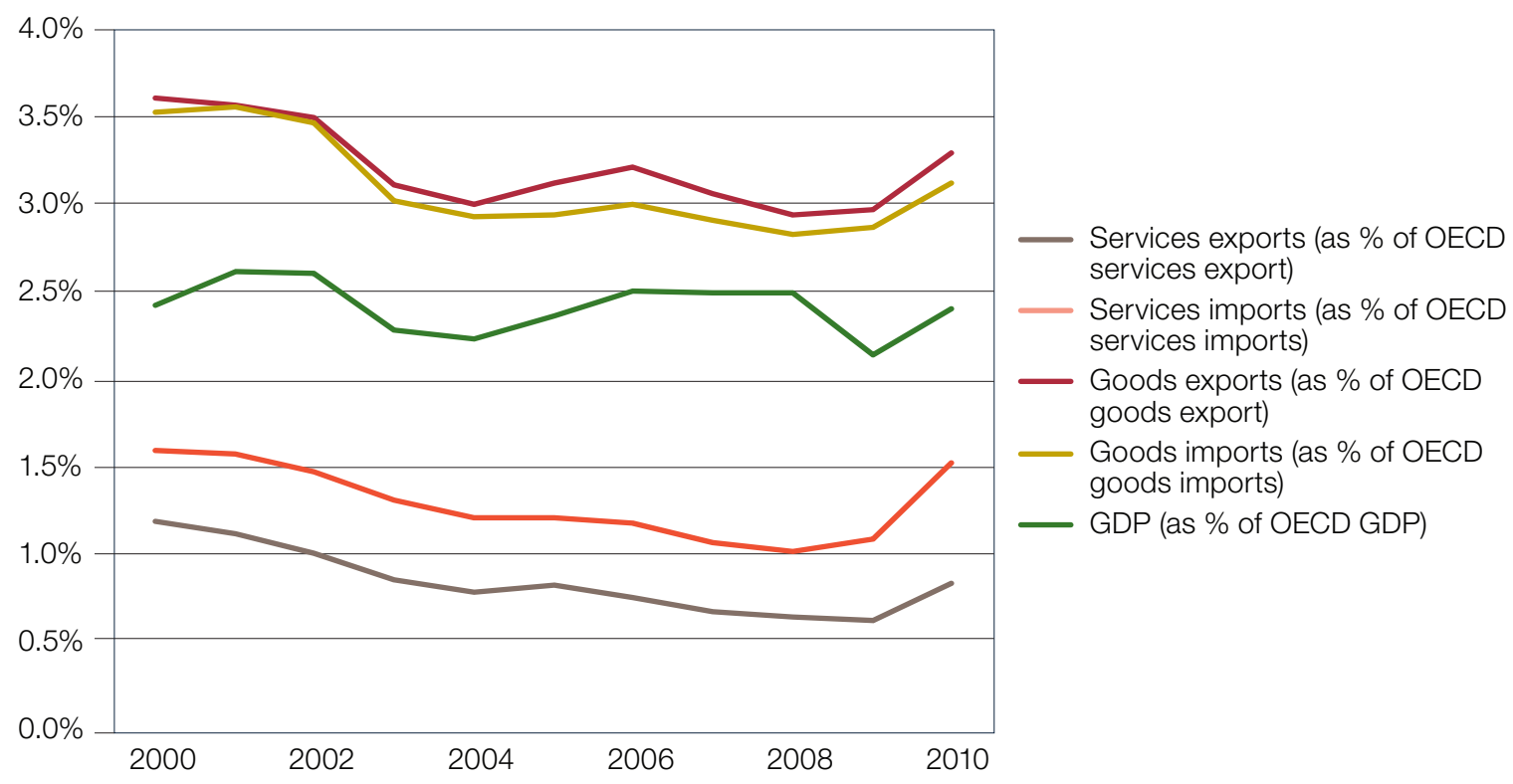

Source: OECD. 
points below the OECD average and the gap is widening. This reflects the impact of some high regulatory entry barriers to services providers. Relying on a broad base of service suppliers is essential for competitiveness in most industries, particularly for firms that produce high value-added goods and services. For example, connectivity through transport and telecommunications links is essential for a successful participation in regional and global production networks. The liberalisation of trade in services would help generate a diversified services sector, increase productivity and boost competitiveness. Consumers would also benefit from lower costs and greater choice.

Mexico has the least developed telecommunications infrastructure of any OECD country, and one of the highest price levels in this sector due to a lack of competition (see chapters 13 and 14). Mexico also maintains foreign-ownership restrictions in the various segments of the transport sector (land, maritime and air transport), and also restricts the movement of people in the professional services sectors at levels that are higher than the OECD average.

Mexico needs to attract more international investment to support jobs and development. It ranks 27 th among OECD countries in terms of the share of inward FDI in GDP, at just $26 \%$. When compared with the OECD average (56\%), and Mexico's proximity to the major traditional sources of FDI (United States and Europe) as well as to the fastest growing sources of FDI in Latin America (China), the potential for Mexico to attract much more FDI in support of jobs and development is clearly significant. Reducing FDI regulation but also improving the business environment is necessary to make the most of this potential.

\section{Further liberalising trade}

Mexico is one of the founding members of the World Trade Organization (WTO) and has been an active participant in multilateral negotiations. It also has one of the world's most extensive networks of free trade agreements (FTAs) and close to $85 \%$ of its trade is carried out under these agreements, particularly the North American Free Trade Agreement (NAFTA) which accounts for over three quarters of Mexico's exports and over half of its imports.

In this context, the December 2010 announcement of a single free-trade agreement with Central America, the expansion of the economic association agreement with Japan and the revival of negotiations for the strategic economic integration agreement with Brazil, are all welcome developments. In November 2011, Mexico formally expressed interest in joining the Trans-Pacific Partnership (TPP) negotiations. This initiative is also welcome, given the importance of the United States for Mexico's trade and the opportunity to strengthen trade relations with additional trading partners.

In keeping with the importance of the external sector for its economy, Mexico's government was one of just a few in the OECD area to include trade liberalisation measures in its counter-crisis measures. Unilateral tariff introduced during the period 2009-2013 are expected to lower the average industrial tariff from $10.4 \%$ in 2008 to $4.3 \%$ in 2013. When fully in place, these reforms will reduce tariff dispersion and in addition will bring Mexico's industrial tariff schedule closer to OECD's. These will further enhance Mexico's competitiveness and its participation in regional and global production networks where the bulk of imports are intermediate inputs. 


\section{Key OECD recommendations}

\section{- Further ease regulatory barriers to FDI.}

- Consider lifting foreign equity restrictions in the transport sector, a key sector whose efficiency would contribute to enhancing Mexico's competitiveness.

- Reform laws and regulations governing the telecommunications sector to boost competition and investment and promote growth in the economy at large.

- Consider lifting restrictions on movement of professional services as a way of boosting Mexico's competitiveness in the services and manufacturing sectors, and enhancing its participation in regional and global value chains.

- Continue the market liberalisation process, unilaterally, regionally and multilaterally to improve the competitiveness of the economy through access to lowest cost - highest quality imports of key intermediate and capital goods, while improving Mexico's ability to export higher valueadded and high-technology products over longer distances. 


\section{Competition and Tackling Public and Private Monopolies}

Lack of competition and excessive regulation have burdened the Mexican economy for many years and contributed to wide income disparities. Policies to improve competition and reduce excessive regulation are part of the policies to improve the business environment but also to reduce poverty and inequalities. A joint Mexico-OECD study suggests that $30 \%$ of household spending takes place in markets where competition is weak and prices are $40 \%$ higher than they could be were the markets more competitive. It is the poorest households, which spend $42 \%$ of their income in such markets, that are most affected. Mexico has already acted on several fronts but more needs to be done to make the most of on recent progress.

\section{Preventing monopolistic practices}

In April 2011 both Chambers of the Mexican Congress unanimously approved the reform of the Mexican competition law, bringing it into line with international best practices. Notably, this substantially increases the maximum level of fines for antitrust violations (up to 10 per cent of a company's annual revenues in Mexico) and makes collusion in cartels a criminal offence. It also strengthens the Federal Competition Commission's (CFC, for its acronym in Spanish) investigatory powers, while also increasing transparency and legal certainty (for example requiring the CFC to publish guidelines and conduct oral hearings). However, for the reform to make a real difference to the Mexican economy the legal framework must be complemented by an effective judicial review system of CFC's decisions, but the last legislature could not agree on such review mechanism.

\section{Improve regulation in the product market}

Regulation in Mexico's product market is among the strictest in the OECD and hinders competition (Figure 13.1). This impedes productivity and curtails growth. The latest OECD aggregate indicator shows that there was little progress from 2003 to 2008. In 2008, Mexico and the OECD launched a project to promote more pro-competitive regulations. The project has already resulted in changes to trade policy and banking regulation; and it has generated recommendations that would yield more than USD 10,000 million in benefits per year if adopted. For example, a joint OECD/CFC study of 2010 found that air fares on routes from or to Mexico City airport are between $40 \%$ and $80 \%$ higher than on comparable routes elsewhere in Mexico. Fares would decrease if entry conditions at the airport were easier and a more efficient mechanism to allocate slots among air carriers were adopted. The economy could also become more efficient and competitive if inward FDI policies were liberalised in certain key sectors, such as telecommunications, TV broadcasting and aviation (a joint OECD/CFC project is in progress; see chapter 12). 
Figure 13.1. Index of regulatory restrictions in the OECD product market

Scale of 0-6: from least to most restrictive

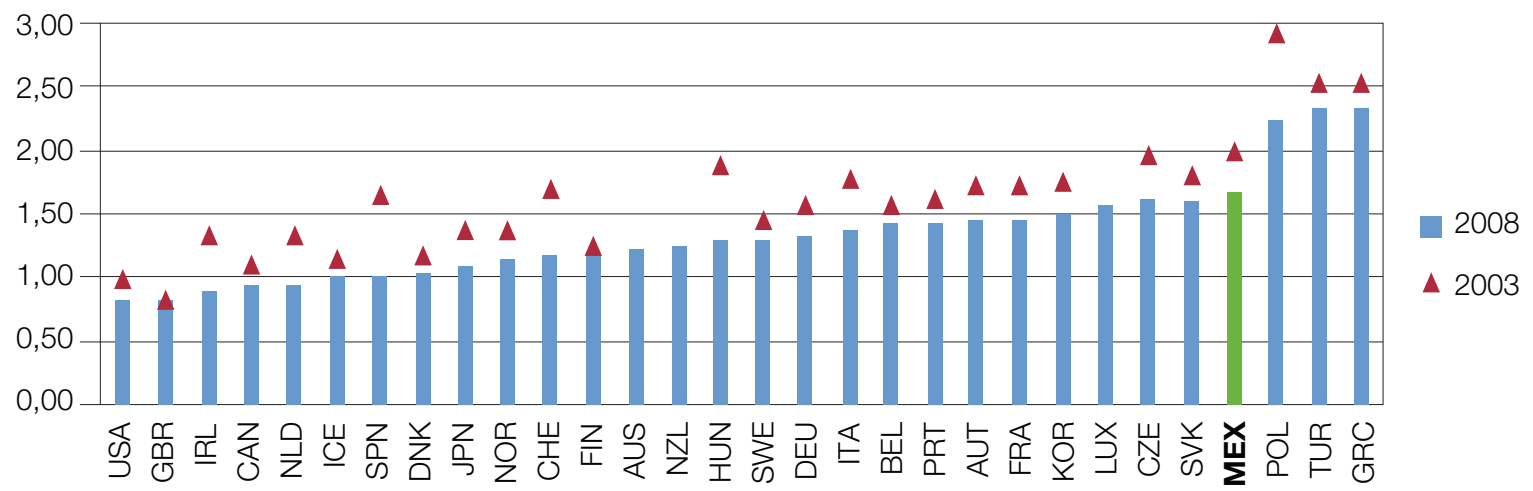

Source: OECD (2011), Product Market Regulation database, http://www.oecd.org/eco/pmr.

\section{Tackling bid rigging in public procurement and improving procurement legislation}

Bid rigging is a problem in public procurement in Mexico. For example, in 2010, the CFC imposed fines totalling MXN 152 million (approximately USD 11.3 million) on six pharmaceutical companies for this offence. Some of the CFC's decisions have already been upheld by the Federal Judiciary Power and the remaining will be reviewed later in 2012. The government has started to take action. As a result of its agreement with CFC and OECD, Instituto Mexicano del Seguro Social (IMSS) is now revising its procurement practices in light of OECD recommendations. The OECD also suggested several changes to the procurement legislation which could make the fight against bid rigging even more effective, such as opening up tenders to foreign bidders and requiring all bidders to submit a "Certificate of Independent Bid Determination". The IMSS-OECD-CFC agreement has spurred other public agencies (e.g. ISSSTE) and state governments (e.g. the State of Mexico) to review their own procurement procedures and bring them in line with international best practices, assisted by the OECD and CFC. Similar initiatives could be undertaken at the state-owned energy companies CFE and PEMEX, which are the two largest public buyers in Mexico.

\section{Open up network industries to competition}

Competition in network industries remains weak. Many state-owned enterprises have been privatised, but the government remains heavily involved in the economy. The energy and water sectors have high levels of public ownership, and their firms are vertically integrated. Redoubled efforts are needed to promote competition in network industries, whether privatised or public sector (see, for instance, chapter 14). Relying on strong, independent and effective regulators is critical.

\section{Improving the corporate governance of state-owned enterprises}

Part of the problem with public-sector monopolies in Mexico is their corporate form. Better corporate governance of state-owned enterprises (SOEs) will help in preserving regulatory and market integrity. Other 
OECD countries have natural monopolies organised as state-owned enterprises (SOEs), but consistent with the OECD Guidelines on Corporate Governance of SOEs, and many have taken steps to separate the State's functions as owner and regulator. In the Mexican parastatal enterprises, where ministers often serve as exofficio board members, concerns arise about regulatory and market integrity. One example is the oil company PEMEX, whose governance was subject of an OECD study in 2010. Without contesting Mexico's constitutional protection of its subsoil, this company could operate in a more market consistent way. Downstream activities not related with public policy objectives could be organised entirely according to commercial principles. Upstream activities that are subject to public policy considerations could be guided by independent regulation and by clear objectives, the implementation of which should be entrusted to a professional and independent PEMEX board of directors.

\section{Key OECD recommendations}

- Following the reform of the Mexican Competition Law, ensure its implementation and regulation, as well as complete the strengthening of the legal framework on competition by establishing an effective judicial review system of Mexico's Federal Competition Commission's decisions and giving the competition authority adequate resources to make the best use of its new powers.

- Continue the review and amendment of laws and regulations that unnecessarily restrict competition.

- Open up network industries to competition. Promote strong, independent and effective regulators.

- Ensure that the fight against bid rigging in public procurement remains a priority among public agencies and promote reforms to procurement laws at the level of Mexican states.

- Keep the fight against bid rigging as a priority and promote legislative and regulatory reform of procurement processes in the country's federative entities

- Reform the corporate governance of state-owned enterprises to separate State's functions as owner and regulator and thus preserve regulatory and market integrity. 


\section{에) $\mathrm{OECD}$}

\section{The Telecommunications Sector}

\section{Reforming the telecommunication sector to boost competition and economic growth}

Lack of competition in the telecommunication sector has resulted in high prices for consumers and businesses and slowed the take-up of new services, as shown by OECD analysis. Inefficient policy and regulatory frameworks have resulted in low penetration of communication services (Figure 14.1) and therefore high market concentration.

Figure 14.1. OECD Basket 2 of fixed broad band subscriptions: 6 GB/15 hours per month. $2500 \mathrm{Mbs} / \mathrm{s}$ and above, September 2011

Dollars PPA

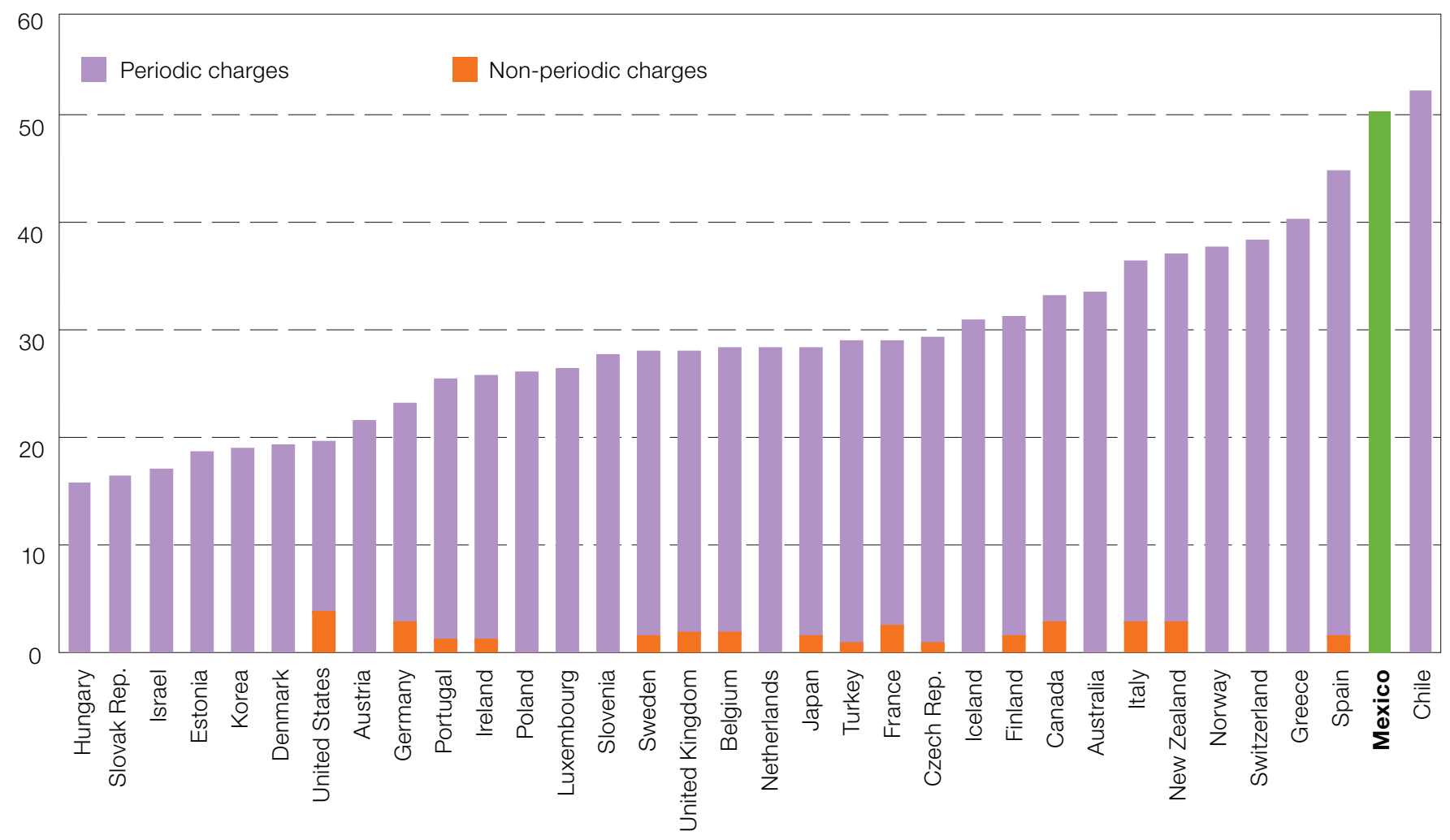

Source: OECD and Startegy Analytics (T-Connect). 
The OECD has made several recommendations to reform the sector and increase competition. Reforming the court system (especially the "amparo" injunction mechanism that enables firms to systematically appeal regulators' decisions) would facilitate the coming into effect of new regulations. The appeal process should be streamlined so as to enable more effective policy making and regulation by the government and regulator rather than by the courts.

It is also important to make the telecommunication regulatory authority Cofetel more powerful and independent, for example, by allowing it to impose higher sanctions than it can today, to deter anti-competitive behaviour. The "double window" ("doble ventanilla"), whereby a regulatory process is conducted twice by two different authorities, should also be removed and the procedures leading to regulatory decisions simplified. At the same time, wider public consultation processes should be put in place to make decision-making more transparent. Moreover, the current concession system should be reformed to simplify and encourage market entry, foster competition, and to draw a clear line between policy and regulatory functions, the latter of which should be transferred to Cofetel with no ambiguity. Cofetel should undertake market reviews in order to determine whether there are dominant players and, if necessary, impose and effectively enforce appropriate remedies, including asymmetric regulation. It should also be authorised to establish non-discriminatory conditions for access to infrastructure resources that are considered bottlenecks, including local loop unbundling.

In addition, foreign investment and ownership restriction in fixed-line networks (currently limited to 49\%) should be lifted to encourage new market entry and investment. Sufficient spectrum resources and from the opticalfiber trunk network, such as that of the Federal Electricity Commission, should be made available to meet the growing demand for mobile broadband data services and for connectivity with the trunk network.

\section{Keeping up the momentum for reforms}

The Mexican authorities have started to implement the OECD's recommendations. First in January 2012, the Mexican Minister of Transport and Communications announced ten measures aimed at implementing the recommendations outlined by the OECD Review of Telecommunication Policy and Regulation in Mexico. More recently he has also announced measures to remove the double window in some processes, which would allow Cofetel to sanction operators directly without having to rely on the SCT to do so. Meaningful fines will act as a deterrent to ongoing anti-competitive behaviour and ensure that regulation is adhered to and that policy objectives to improve services are met. The SCT also published, on March 28, 2012, a list of 6,400 government facilities that will be made available to telecommunication operators for the installation of telecommunication equipments, to improve coverage and quality of service.

In addition, Cofetel is strengthening its transparency and accountability standards by issuing new consultation procedures on draft regulatory proposals. It announced on April 25, 2012 that it will launch a public consultation on costing methodologies and models for interconnection.

It should be noted that the Supreme Court rulings on interconnection rates have had a clear influence on the market. Smaller operators now pay much lower interconnection rates to terminate calls on Telcel's network and some operators have launched more attractive mobile phone-services packages. 
Finally, in May 2012 the CFC accepted a set of commitments proposed by Telcel (the largest mobile operator) to close an antitrust investigation and withdraw a previously imposed fine of USD 1 billion. The commitments include agreeing to reduce interconnection tariffs, ceasing pending litigation processes on interconnection and offering calling plans per minutes that can be used for both off-net and on-net calls.

This momentum for reform needs to be maintained, for it will greatly benefit Mexican consumers and businesses and lead to greater economic and social development.

\section{Key OECD recommendations}

- Continue to advance reforms in the telecommunications market aimed at simplifying and stimulating the entry of new operators and ensuring a competitive environment with lower prices and better quality services.

- Reform the Mexican judicial system (particularly in terms of the amparo injunction procedure) to avoid abuse involving the suspension and systematic overturning of regulatory policy decisions.

- Give greater powers and independence to Cofetel, enabling it to impose higher economic sanctions, regulate interconnection fees ex ante, undertake market analysis to establish nondiscriminatory conditions for access to essential infrastructure resources, including local loop unbundling.

- Introduce measures to eliminate the "double window" and separate policy-making functions from those of market regulation and supervision. 


\section{Regulatory Policy}

Over recent years, Mexico has taken a number of steps aimed at improving its regulatory policy in order to support entrepreneurial and business activity and reduce incentives to informality. Regulatory policy to ensure that the regulatory lever of government works effectively, so that regulations and regulatory frameworks are of the highest quality, meet policy objects efficiently and are in the public interest is indeed of critical importance in shaping economic performance and social welfare. In other OECD countries, economic growth and development have been promoted through regulatory policy's contribution to structural reforms, liberalisation of product markets, international market openness, and a less constricted business environment that fosters innovation and entrepreneurship. Regulatory policy can also support the rule of law through initiatives to simplify the law and improve access to it, as well as improvements to appeal systems. Regulatory policy also supports quality of life and social cohesion, through enhanced transparency which seeks out the views of the regulated, and programmes to reduce red tape for citizens.

Recent steps to improve regulatory policy in Mexico include an update to its system of Regulatory Impact Assessment (RIA) - the primary and most important tool across OECD countries to ensure the quality of new regulation. The Federal Regulatory Improvement Commission (COFEMER, by its Spanish acronym) has been employing RIA for more than a decade, and there is now a sophisticated RIA and public consultation system in Mexico, which is well embedded in the regulatory drafting culture of the country (Figure 15.1). Similarly, Mexico has adopted the internationally recognised Standard Cost Model, which has brought a renovated impetus across the federal public administration to reduce administrative burdens generated by formalities. There is also a renewed emphasis on training and capacity building: COFEMER is delivering a "Diploma in Regulation", with more than 6,000 graduates, the large majority being public officials at federal, state, and municipal level. Regulatory policy programmes and initiatives have also been adopted by most of the 32 Mexican states and many municipalities. However, their degree of development, institutionalisation and performance vary widely.

It is important for Mexico to continue to improve regulation policy and develop a regulatory policy culture. Successful promotion of the culture of better regulation in other OECD countries and notably the United Kingdom with the Better Regulation Executive, can help moving forward in this direction.

\section{Embrace a "whole-government" culture for regulatory policy in Mexico}

COFEMER has played a key role in enhancing regulatory quality and, as a result, Mexico is currently at a stage where positive results are being obtained. Nevertheless, COFEMER is not the only entity responsible for regulatory policy within the Mexican administration. Line ministries and sectoral regulators should recognize the important and key role they play in adopting and promoting a better regulation culture. Mexico should consider establishing a strong coordination network to bind the work of different parts of the administration 
Figure 15.1. Degree of sophistication* of the Regulatory Impact Assessment process 2005-2008 (RIA 1)

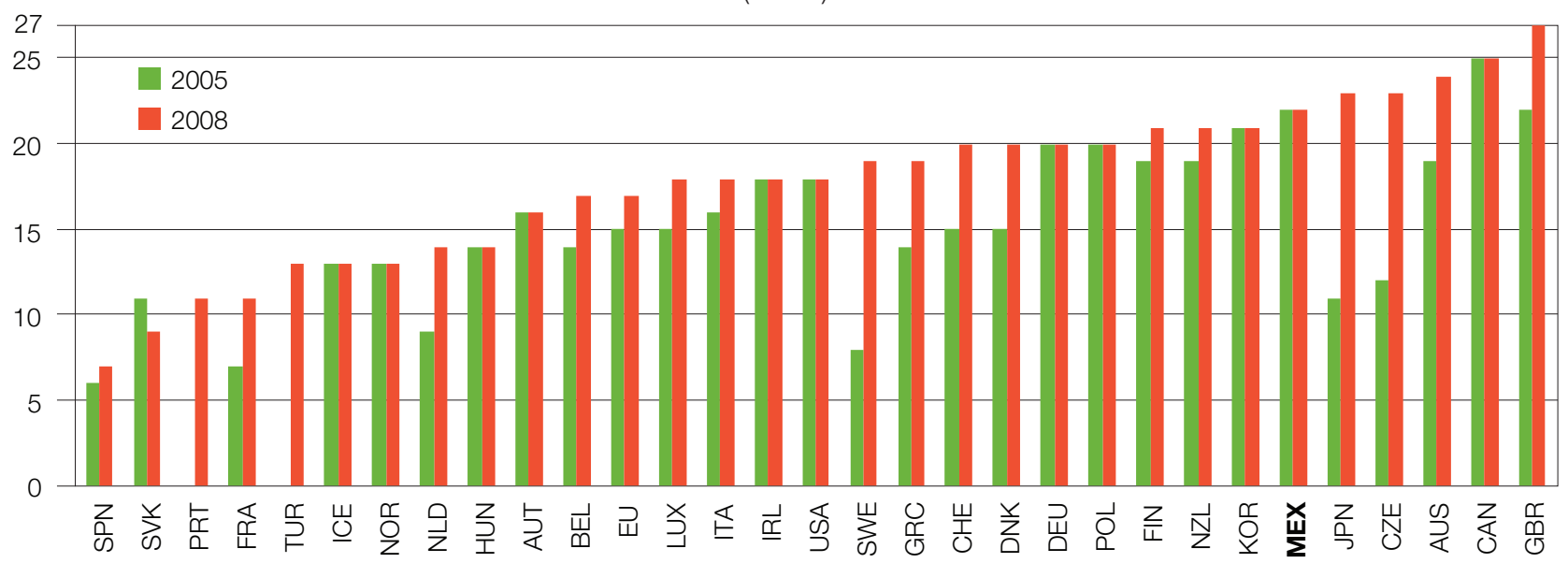

Note: *Greater sophistication reflects a more fine-tuned and broad-based evaluation process, leading to better regulation. Source: OECD (2009), Indicators of Regulatory Management Systems, 2009 Report, available in www.oecd.org/dataoecd/44/37/44294427.pdf.

on regulatory policy. The objective should be to generate ownership of improving the regulatory policy agenda within ministries and within the other entities of the public administration, and make them directly responsible and accountable of their regulatory performance to businesses, citizens, and the society at large.

Nonetheless, a profound culture of regulatory improvement cannot be achieved without involving the legislature, since this is the primary source of laws from which secondary regulation emanates. Therefore, the Mexican Congress should also consider adopting specific tools of regulatory policy as part of their legislative activities. For instance, the legislative power should consider adopting techniques for ex ante and ex post evaluation of the impact of legislation. Transparency in the process of law making should also be enhanced through the inclusion of formal and institutionalised public consultation.

\section{Achieving a comprehensive regulatory policy culture}

COFEMER requires a strengthened institutional structure in order for Mexico to achieve a comprehensive regulatory policy culture. The Commission needs an institutional design that grants it sufficient legal and financial autonomy to discharge its mandate as a central oversight body for regulatory quality. Such autonomy would reinforce its technical independence, protect its professionalism, and distance it from the cyclical influences within the Mexican public administration. A more robust institutional setting would locate COFEMER close to core executive functions, either from the office of the presidency or as part of a central ministry with significant coercive power. This would allow COFEMER access to the highest political levels to preserve influence within government.

\section{Key OECD recommendations}

- Establish a network approach to ensure regulatory quality inside the federal public administration, which might include better regulation units inside ministries. 
- Revise the institutional structure of COFEMER to grant it sufficient legal and financial autonomy, and consider its incorporation into the office of the presidency or into a ministry with high coercive power.

- Increase accountability of RIA for line ministries and regulators, by considering a requirement that the Minister responsible would certify the quality of the RIA.

- Establish public consultation on draft regulations from the early stages of regulatory development under the responsibility of the Ministry in charge, and under supervision of COFEMER.

- Continue using the Standard Cost Model in the biennial programs for regulatory improvement so as to establish the programme of measurement and reduction of administrative burdens as a permanent feature.

- The legislature should take measures to adopt a regulatory quality culture by adopting ex-ante or ex-post assessment of legislation, greater transparency in rule-making and systematic public consultation.

- Sub-national governments should establish better regulation policies that address all the stages of the regulatory governance cycle - their creation, implementation, supervision and ex post evaluation - and be participatory and permanent. 
grant greater law enforcement powers to the Ministry of Public Administration (SFP, by its Spanish acronym) in foreign bribery cases.

\section{Improving corporate governance}

As an adherent to the OECD Principles of Corporate Governance, Mexico has actively worked to improve its legal and regulatory framework. Its Securities Law (2006) represents significant progress in establishing more stringent listing requirements for use of audit committees, independent directors and disclosure. The securities regulator, National Banking and Securities Commision (CNBV, by its Spanish acronym) has also promoted the enforcement of law by requiring companies to disclose to what extent they follow the recommendations of Mexico's voluntary corporate governance code. However, the corporate governance framework of Mexico still has shortcomings, including inconsistencies between securities law and company law requirements, which undermine their effective enforcement. Harmonizing corporate law with securities legislation would increase legal certainty and help judges to more consistently enforce the overall framework.

\section{Improving the climate for international investment}

Another challenge for Mexico in building a better business environment concerns its discriminatory treatment of international investment, which has hampered its ability to attract more investment in support of job creation, innovation, and development. Mexico maintains one of the most restrictive policy regimes towards foreign investors, even surpassing that of other Latin American countries such as Brazil, Chile and Colombia (Figure 16.1). This is largely due to a screening mechanism which most OECD countries have long since done away with, as well as significant sectoral restrictions in transport, media and fixed telecoms, amongst others. This poor regulatory performance is similarly reflected in Mexico's low ability to attract FDI (see chapter 12).

Mexico could take a number of steps to improve the current climate for international investment and raise its profile as a country that welcomes international investment. In many instances, these steps do not entail heavy regulatory or legislative reform. For instance, it should evaluate whether the laws and regulations restricting international investment might be replaced with non-discriminatory measures that could achieve the same policy objectives but at lower price. Commitments under international investment agreements, including the OECD Codes of Liberalisation of Capital Movements and Current Invisible Operations, have a high-level of visibility among prospective investors and international investment partners and improving these commitments would create greater certainty and legal security in the eyes of international investors.

Responsible business conduct is of increasing importance to international investors, who want to know that their efforts in this area will be supported by the governments in the countries in which they invest. With the recent update of the OECD Guidelines for Multinational Enterprises, there is an opportunity for Mexico to promote a level playing field for all businesses, whether domestic or international. 
Figure 16.1. OECD Foreign Direct Investment Regulatory Restrictiveness Index

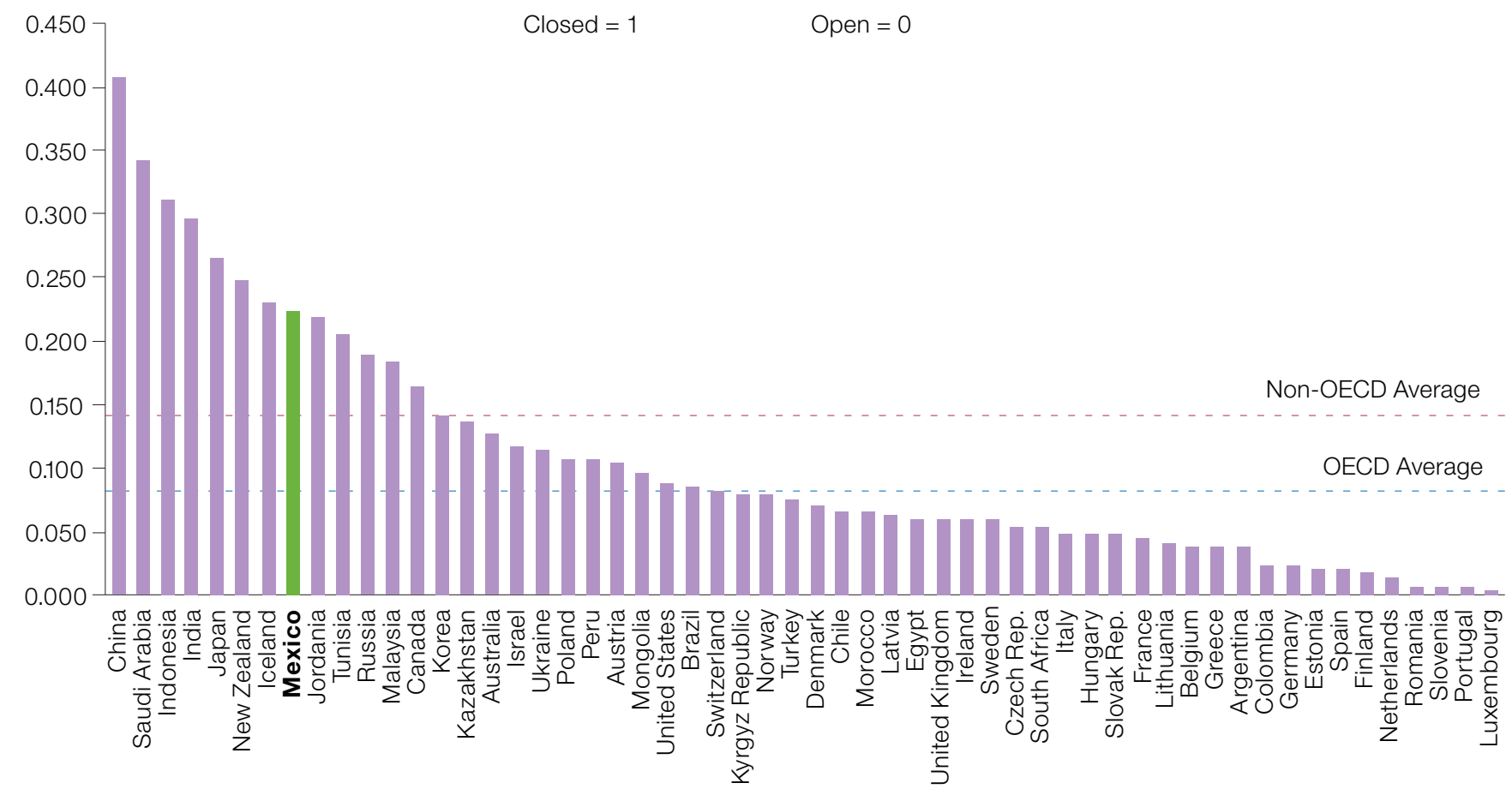

Source: OECD.

\section{Key OECD recommendations}

- Strengthen the rule of law by implementing more broadly ongoing reforms to state judicial systems; strengthening property rights and ensuring a more effective law enforcement.

Follow the recommendations of the OECD Working Group on Bribery.

- Ensure consistency between securities law and company law requirements to improve legal certainty for businesses and enforcement.

- Review laws and regulations that restrict international investment with a view to abolishing those that are no longer in use

- Strengthen Mexico's commitments to international investment agreements, including the OECD Codes of Liberalization of Capital Movements and Current Invisible Operations. 


\section{Green Growth}

Mexico has been at the forefront of the efforts of promoting green growth, and has taken important steps to integrate green growth into its policy and institutional framework in areas such as energy, water, agriculture and transport. Mexico has also played a leading role in promoting green growth on the international scene, notably by establishing 'sustainable development, green growth and the fight against climate change' as one of the five priorities of the 2012 G-20 Mexican Presidency.

\section{National green growth plans and policy instruments}

Mexico's incorporation of sustainability concerns in the national development planning process is mainly provided through setting environmental sustainability as one of the five key pillars of the National Development Plan (NDP) by the federal government. The NDP integrates sustainable water, forest and biodiversity management as well as commitments to contribute to tackling climate change and reducing solid and hazardous waste. Structural reforms for greener and more inclusive growth are further encouraged through several other initiatives.

Achieving green growth in Mexico will require further enhancing the integration of environmental concerns into national and sectoral policies and increased policy coherence in economic sectors, especially energy, transport and agriculture. Improving efficiency in the state-run electricity and oil industries is key to meeting Mexico's ambitious target to achieve a 50\% reduction of greenhouse (GHG) emissions by 2050 compared to 2000 . Mexico has worked to reform the fuel price stabilisation fund and reduce subsidies to electricity, diesel, gasoline and liquefied petroleum gas (LPG) which amounted to as much as $1.5 \%$ of GDP in 2005-2009. However, despite efforts to promote coordination (for example, between environment and agriculture Ministries), political and economic constraints have thwarted progress in eliminating environmentally-harmful subsidies.

Better targeting of energy subsidies, while bringing prices more in line with costs, is one of Mexico's declared goals in its energy strategy. The government has started to implement a cash-transfer scheme connected to Oportunidades to help poor households cover their energy needs with fewer distortions than under the current system. Mexico has also started an interesting pilot programme to replace electricity subsidies for pumping irrigation water with direct cash transfers in some states, thus removing the price distortion and the incentives for over-use of scarce water resources. However, Mexico needs to do more to bring energy prices more in line with costs. Despite welcome efforts to gradually increase gasoline, diesel and LP gas prices, the subsidies remain in place and are likely to increase further when international oil prices rise. Furthermore, little has been done to remove electricity subsidies which should be gradually withdrawn in line with the government's goals. It will be much more efficient to extend cash benefits to the poor and help the most vulnerable citizens to cushion the impact of such measures on their family economy. 

Figure 17.1. Revenues from environmentally-related taxes in selected countries, 2010

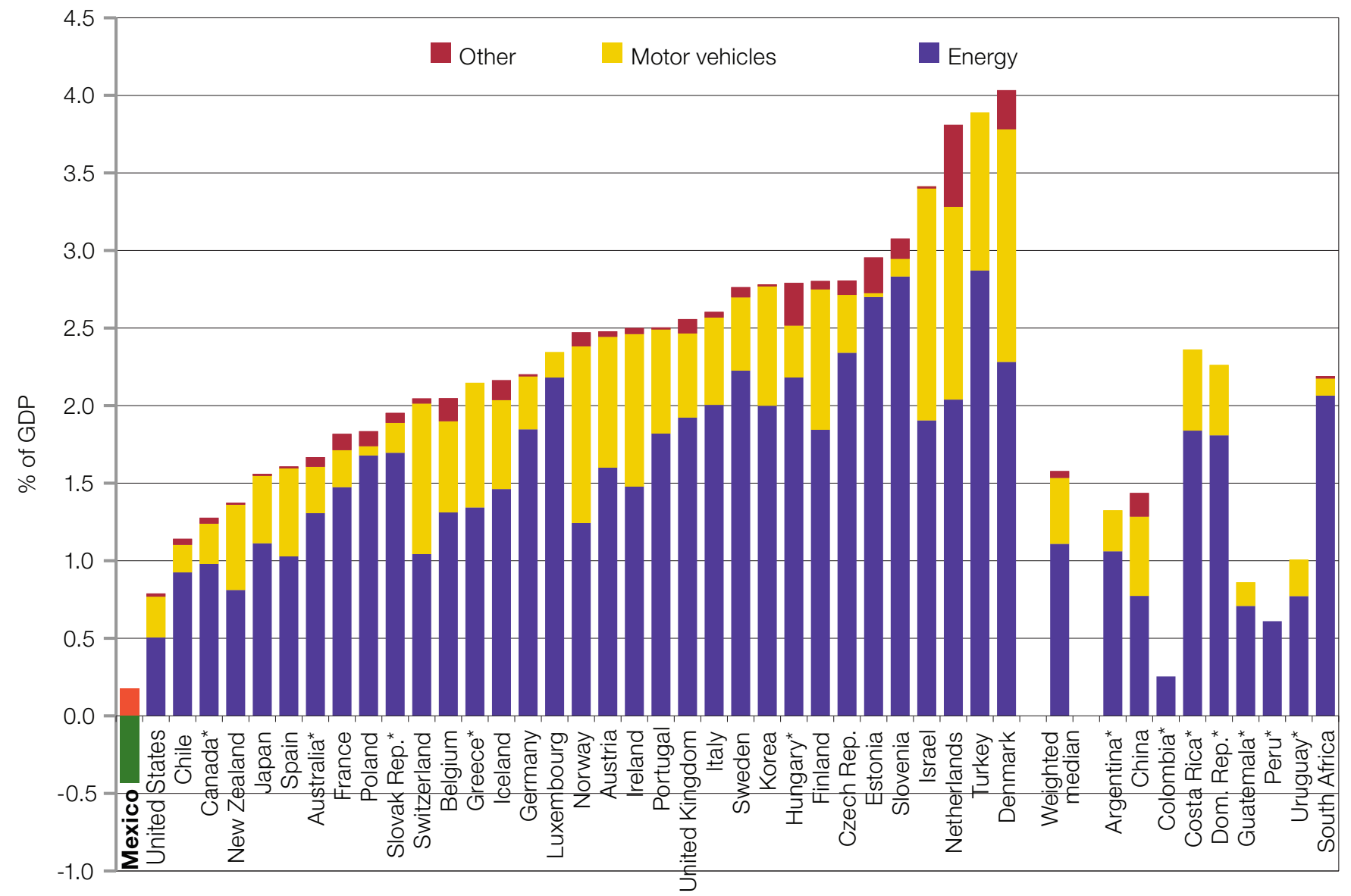

Note: Figures for countries marked with $\left(^{*}\right)$ correspond to 2009. Otherwise, figures refer to 2010.

This figure illustrates revenue from environmentally-related taxes, by tax base, as a percentage of GDP. In Mexico, fluctuations in consumer prices on motor vehicle fuels are smoothed out. The system used to stabilise fuel prices for the final consumer means that tax revenue becomes negative in years where world market prices for those fuels are high. As a result of the higher oil prices on world markets in late 2010, the excise duty on fuels turned into a subsidy equivalent to about 0.5\% of GDP. Although other countries also support fossil fuel consumption and production, they generally do not do so through the tax system and therefore are not shown in this figure.

Source: OECD/EEA database on instruments for environmental policy; www.oecd.org/env/policies/database

energy subsidies while extending cash transfers to the poor, i.e. through an expansion of the Oportunidades Program or the introduction of a social assistance benefit.

- Introduce broad-based greenhouse gas emission taxes or an auctioning of emissions permit system.

- Modernize public transport systems and reflect environmental considerations into transport planning and management.

- Make further progress on the integration of environmental concerns into agriculture, energy, transport and other sectoral policies. 
to consume more energy and invest less in energy efficiency, reducing energy security and raising GHG emissions, and are therefore inconsistent with Mexico's green growth strategy (see chapter 17).

Removing electricity subsidies and introducing carbon pricing over time would be fiscally and environmentally more rational. To some extent participating in auctioning of emissions permits systems would be more attractive for Mexico than raising carbon taxes, as this opens up opportunities to obtain funds from abroad to finance investments in energy efficiency. It would also be more efficient, in the sense that it would ensure that households exploit the cheapest mitigation strategies first. Such a policy could be complemented with subsidies for lower-income households to invest in highly energy-efficient appliances.

\section{Efficient energy production}

Mexico uses essentially nationally-produced gas, oil and coal for its energy generation. Over recent years, the two fundamental drivers of change in the Mexican energy mix have been the decreasing productivity of Mexico's most important oil field (Cantarell), and the emergence of unconventional gas production in the United States, which led to a significant drop in the regional gas price. In consequence, Mexico's US gas imports increased fivefold, mainly for use in gas-fired power plants. The share of fuel oil in the Mexican power mix fell sharply from $61 \%$ to $21 \%$ between 2000 and 2010, whereas the share of natural gas has risen from $20 \%$ to $55 \%$. A major expansion of natural gas infrastructure has recently been announced, adding more than 4,300 $\mathrm{km}$ to the transportation pipelines between 2010 and 2020 with associated investments of more than USD 8,300 million. In addition, discussions about how to use the country's abundant domestic shale gas resources are under way.

Mexico's abundant resources make it one of the most promising countries for shale gas development globally. Its 19 trillion cubic metres of shale gas is the fourth-largest shale gas resource base in the world after China, the United States and Argentina; this figure represents some $85 \%$ of Mexico's remaining recoverable gas resources. While known about for more than two decades, as elsewhere, shale gas was not considered economically viable to produce until recently. Shale gas could make a significant contribution to meeting Mexico's gas needs in the longer term, but much will depend on the regulatory regime governing participation by private companies and whether the environmental challenges -notably related to the use and recycling of water for hydraulic fracturing- can be overcome. Assuming private investments and a sound environmental regime, the International Energy Agency forecasts Mexican unconventional gas production to reach about 37 billion cubic metres in 2035 , close to $45 \%$ of the country's total gas production.

The need for private investments in the energy sector is not confined to the area of unconventional oil and gas. More generally, maintaining the level of oil and gas production will depend on tapping international financial and technological resources and reducing Pemex's fiscal burden. For example, in 2011 Pemex paid more in taxes and duties than its gross income, resulting in an artificial "loss". To this end, Mexico needs to further pursue the reform efforts begun by the 2008 energy reform. Although the first performance-based service contracts were awarded in 2011 and 2012, these were restricted to mature oilfields. It remains uncertain whether private investors will be willing to risk capital to enter the agreements in their current "cost-plus" form once they are applied to deepwater or shale exploration. 

Figure 18.1. Scenarios for sectoral contributions to reduce $\mathrm{CO}_{2}$ emissions in Mexico

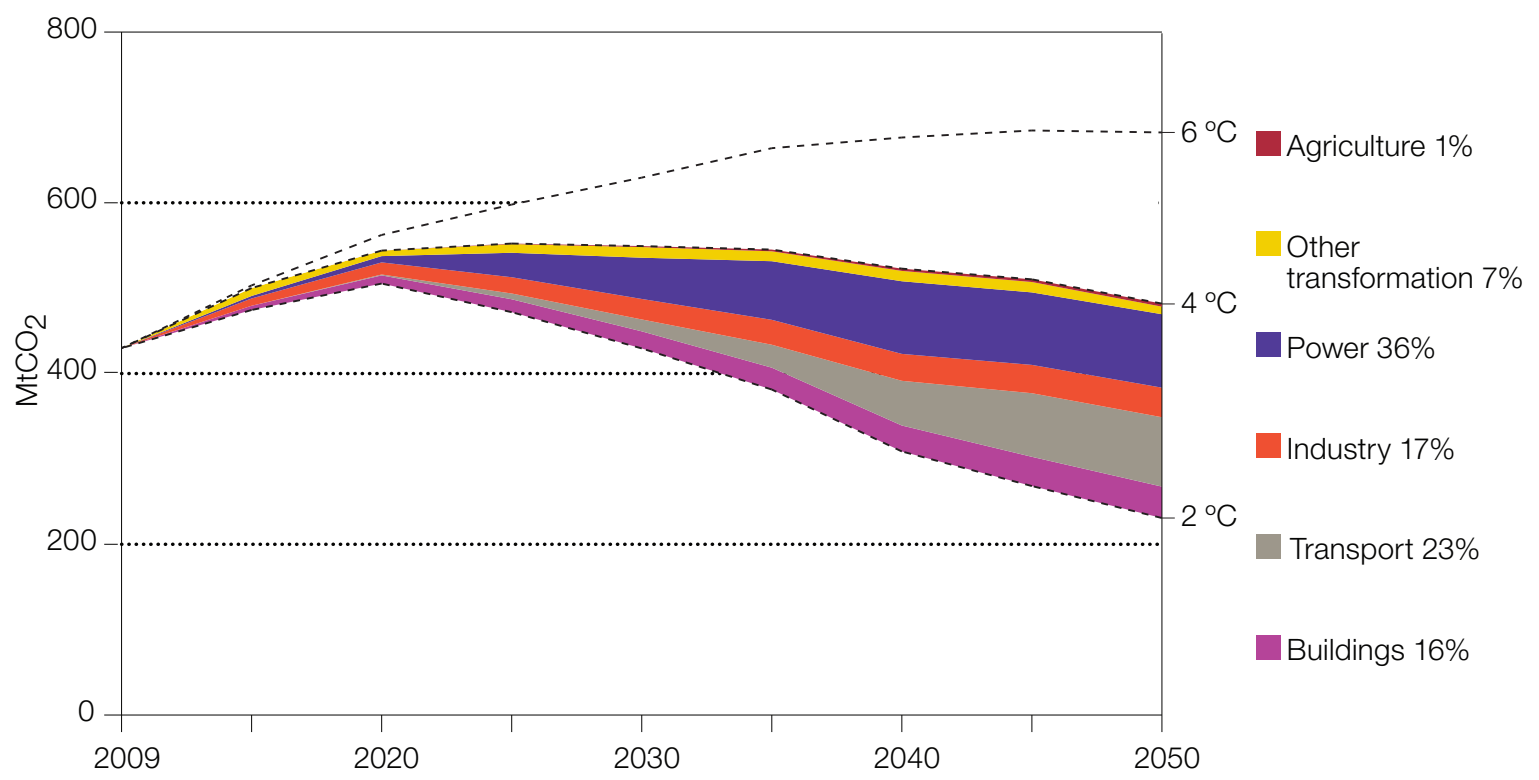

Source: International Energy Agency (2012), Energy Technology Perspectives 2012, OECD/IEA, Paris, p. 590.

Figure 18.2. Mexico's electricity mix in the 4 and 2 degree target scenarios

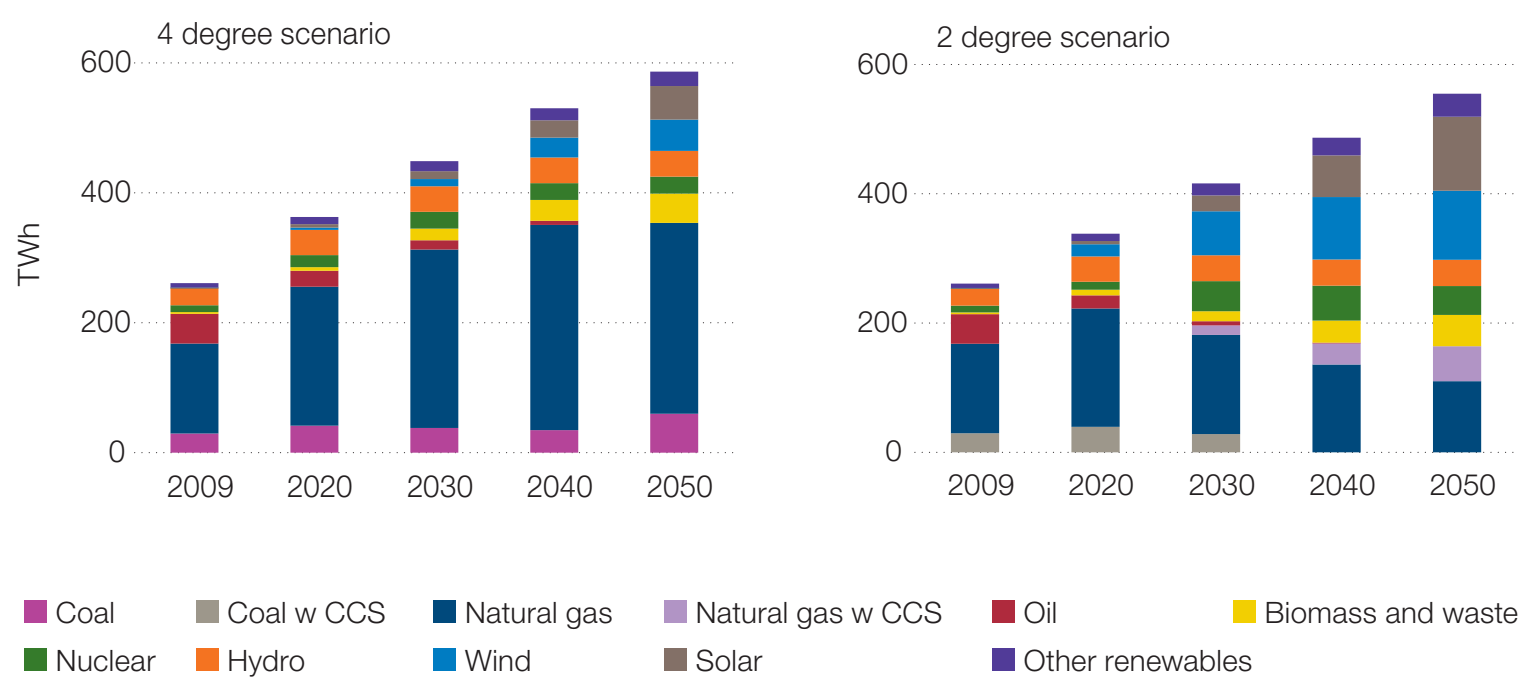

Source: International Energy Agency (2012), Energy Technology Perspectives 2012, OECD/IEA, Paris, p. 595. 


\section{Key OECD recommendations}

- Remove remaining energy subsidies to ensure policy coherence with GHG emissions reduction targets.

Consider an auctioning of emissions permits system.

- Continue to reform the investment framework for the oil \& gas sector to allow for higher levels of private investment.

- Put in place a robust and appropriate regulatory regime for the exploitation of shale gas, with sufficient staff and expertise.

- Reform the planning methodology of the Federal Electricity Commission in order to enable the utility to tap renewable energies more systematically in the future. 


\section{The Agriculture Sector and Rural Areas}

In 2010, Mexico's agriculture sector accounted for just 3.6\% of GDP, but employed $12.7 \%$ of the labour force. Agriculture is less productive than other sectors in the economy and is characterised by a marked duality between a large number of small farms (two hectares or below), producing food mostly for their own consumption and a small number of extensive large-scale, commercial farm holdings (more than 50 hectares) that account for a large proportion of agricultural output. Mexico is a net importer of agribusiness products (with a trade deficit of USD 3.6 billion in 2010). The challenge is therefore to both improve the competitiveness of the sector and turn it into a new source of growth and reduce poverty.

Over the past two decades, Mexico has been implementing a number of agricultural and related trade policy reforms with this double objective. Agricultural reforms were also accompanied by opening up of the economy to international trade through unilateral, regional and multilateral efforts. These efforts, together with the implementation of direct payments to farmers via the Programme of Direct Support for the Countryside (PROCAMPO, by its Spanish acronym), have reduced distortions and improved farmers' income. Overall government support to producers has been reduced from 28\% of gross farm receipts between 1991 and 1993 to $12 \%$ between 2009 and 2011 and now below the OECD average of around 20\% (Figure 19.1). This a very welcome development as government support to producers usually distorts production and trade while doing relatively little to improve productivity and competitiveness, ensure sustainable resource use or help farmers cope with risk. During 2009-2011, government support based on output prices (one of the most distorting forms of intervention) accounted for $24 \%$ of producer support, payments based on input use accounted for $50 \%$ (variable input-related payments contributed 24\%, payments for on-farm investment and services 26\%), and other less distorting support payments the remaining $26 \%$.

\section{Further improving competitiveness and addressing poverty issues}

Even though the situation has improved following the introduction of PROCAMPO in 1994, large producers continue to benefit disproportionately from agriculture support. Support is insufficiently focused on public investments to improve sustainable agriculture productivity growth and well-targeted social programmes. Public spending on research and development, agriculture training and education, and food inspection services is relatively low compared to the OECD average. These types of support would facilitate investment, innovation and enhance the overall performance of agriculture.

In addition, better risk management policies would provide farmers with the tools needed to manage their own risks. In some cases, this might best be done by providing information and training to help farmers identify and cope with normal farming risks. Public support may also be needed to help farmers cope with unavoidable catastrophic risks, such as recent droughts. In this case, support needs to be defined in advance, with clear 
Figure 19.1. Composition of Total Producer Support Estimate (PSE) by country, 2009-2011

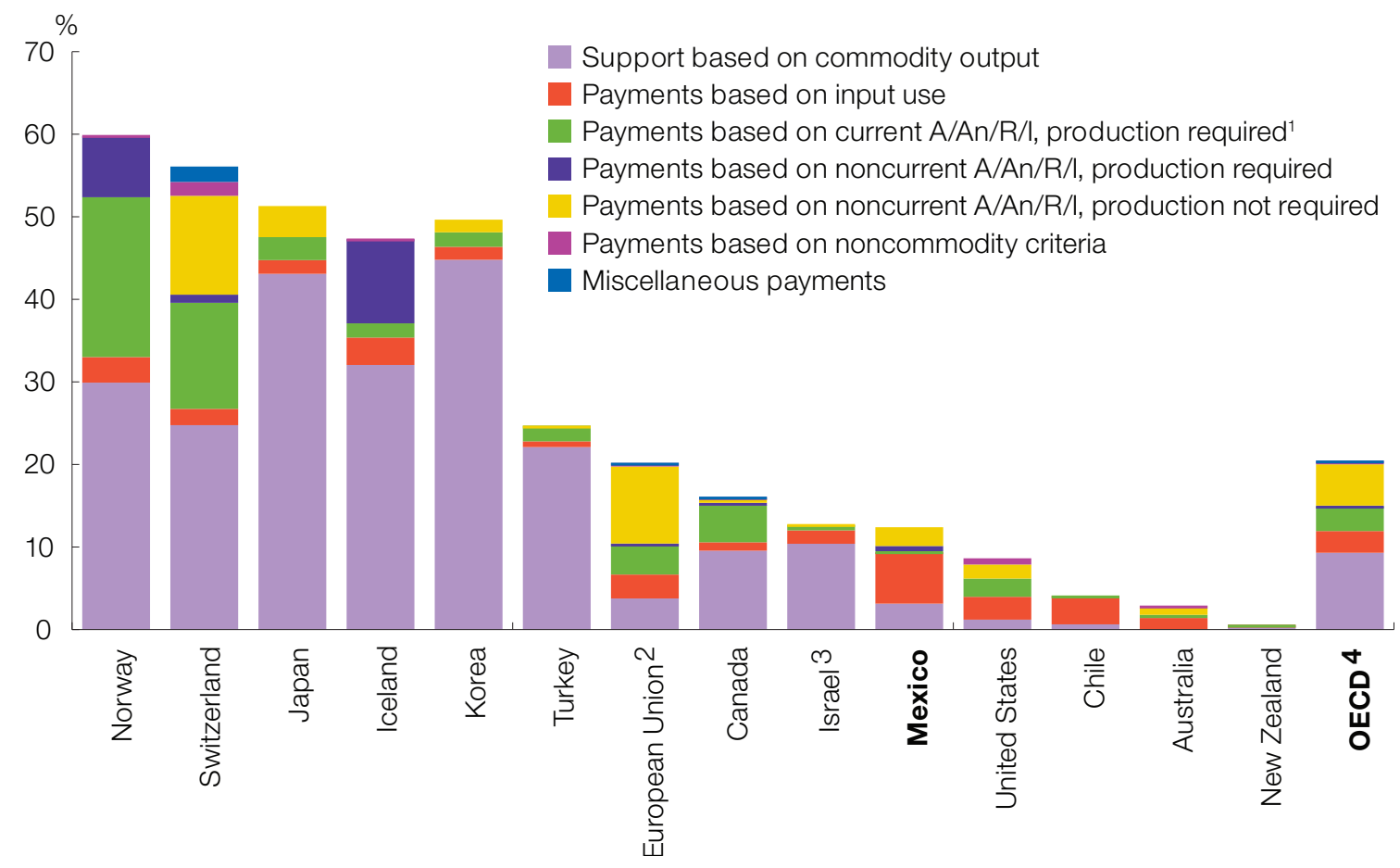

1. A (Area planted), An (Animal numbers), R (Receipts), I (Income). 2. EU27 in 2009-2011. 3. The statistical data for Israel are supplied by and under the responsibility of the relevant Israeli authorities. The use of such data by the OECD is without prejudice to the status of the Golan Heights, East Jerusalem and Israeli settlements in the West Bank under the terms of international law. 4. The OECD total does not include the non-OECD EU member states.

Source: OECD, PSE/CSE database, 2012.

and predictable parameters. The large increase in subsidies to price hedging contracts requires a rigorous evaluation in terms of its cost effectiveness to manage risk at the micro level; i.e. for the individual producer.

Another challenge is to develop policies that simultaneously enhance sustainability and efficient water management and support agricultural production. Since 2000, subsidies for inputs and services such as energy used by farmers have been increasing (mainly to pay for pumping water for irrigation). These subsidies are many times higher than payments recently introduced to support infrastructure for better water management (see chapter 20). Reducing or eliminating electricity and fossil fuels subsidies for water pumping would improve the consistency between agricultural policies and environmental sustainability. Moreover, decoupling support from the volume and type of agricultural production, or the use of specific inputs, has been shown to improve the efficiency of support to agriculture.

\section{Institutional challenges for the development of rural areas}

Over half of Mexican territory operates under some type of social ownership - ejidos or agrarian communitiesin which special management regimes govern both collective land and land plots granted to individuals. Reforms of the community land system in 1990 had limited impact. Although considered socially important 
given the absence of broader social safety nets, some of the provisions undermine investment in, and efficiency and adjustment capacity of the agriculture sector.

Agricultural policy is also rendered less effective by a lack of clarity in institutional roles among the many government agencies involved in agriculture, fisheries and rural development in Mexico. Duplication of activities and sometimes inconsistent approaches across the full range of government programmes have diminished the impact of Mexico's significant public expenditures in the sector.

From the rural development standpoint, the priorities for Mexico's rural zones include: (1) poverty reduction; (2) the provision of core public services; (3) strengthening of agricultural productivity and diversification of the rural economy; and (4) net exploitation and conservation of natural, cultural, and energy resources. These priorities go beyond the scope of action of any ministry, so institutional coordination is needed to carry them out efficiently. Although the Special Concurrent Programme (PEC, by its Spanish acronym), represents a major effort to design an integrated federal policy for rural development, in its current state is more an inventory of programmes than a tool to exploit synergies among them and consolidate a coherent strategy.

\section{Key OECD recommendations}

- Strengthen consistency between agricultural policies and environmental sustainability, in particular by reducing or eliminating electricity subsidies for water pumping and fuel subsidies.

- Shift agricultural support towards targeted investments in innovation and infrastructure, moving away from subsidies on variable inputs and price-related measures, in order to improve sector performance and competitiveness.

- Consider phasing out current restrictions on land ownership and trading when social policies and safety net are sufficiently developed.

- Review and clarify PROCAMPO's objectives with a view to targeting the available funds to explicit goals and intended beneficiaries.

- Strengthen the Special Concurrent Programme (PEC) which covers policy initiatives within different departments that are related to rural areas by developing a coherent, horizontal strategy covering infrastructure, health, education, social and environment policy areas to foster development in rural zones.

- Strengthen risk management policies by providing information and training to farmers and helping farmers cope with unavoidable catastrophic risks. 
Tailored policy recommendations will be available in a final report (November 2012), building on OECD tools and concepts (Guidelines for effective management of multi-level governance; Principles for financing water management; Checklist for Public Action; Strategic Financial Planning; etc.) as well as lessons learnt from OECD member and non member countries. They will provide guidance for policymakers to continue the efforts engaged to make water reform happen.

\section{Key OECD recommendations}

- Maintain the strategic vision and leadership reflected in Mexico's 2030 water agenda, and develop an action plan for its implementation with a whole of government approach, which promotes consistency between these policy areas, including agriculture, and collaboration between government levels. This plan should define priorities, align targets, and create mechanisms to monitor federal, regional and state water plans and programmes.

- Develop an integrated policy framework for financing the water sector. Specify the objectives, principles and financing mechanisms, considering both sector income and expenditure, as well as the functions of the three levels of government and key stakeholders. Include in the financing strategies principles such as the polluter pays, the beneficiary pays, equity, policy consistency and alignment of incentives.

- Take full advantage of the benefits of existing economic tools for water management: adjust rates to promote more efficient water use, target water to places where it creates greater value added and cover at least the operating and maintenance costs of hydraulic infrastructure; increase charges for water extraction by sector firms and farmers (at least when they exceed the permitted quota) to create awareness of the scarcity of water; and evaluate the impact of farm subsidies on water use, with a view to reforming them or gradually phasing them out.

- Strengthen the role, prerogatives and autonomy of river basin authorities and their auxiliary agencies, to turn them into government entities with capacity to design policies adapted to the local context, to identify the necessary projects and to develop financing plans that generate sufficient resources to operate adequately and fulfil their responsibilities.

- Review the regulatory framework governing the supply of water services with the aim of resolving redundancies and omissions in regulatory functions, precisely identifying responsibilities at each level of government, and strengthening their application and compliance. Target efforts on strengthening the capacity and financial sustainability of the agencies, efficiency and quality of service provision, and capacity to respond to users. 


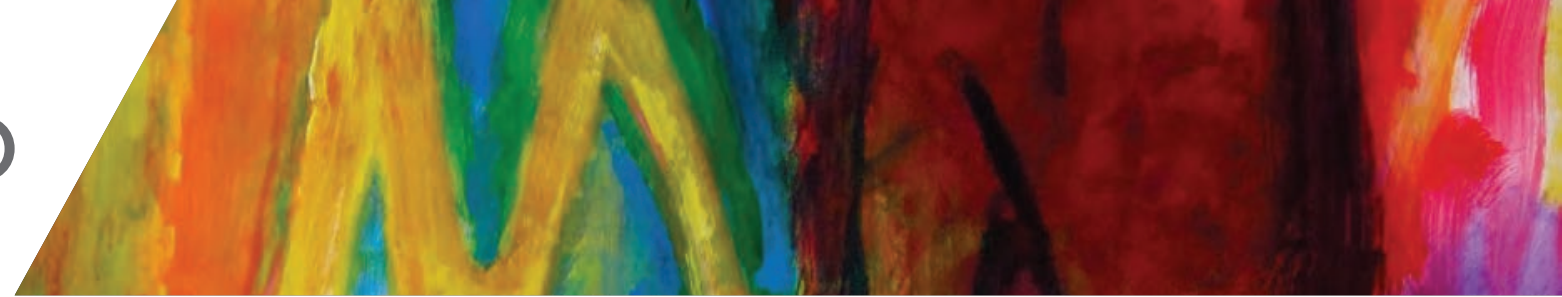

\section{Security and its Economic Impact}

\section{A potentially large economic impact}

According to recent surveys, security is one of the top concerns of Mexicans today - more important even than economic and social issues (see, for instance, Latinobarómetro). The same surveys also suggest that citizen confidence that the government can tackle the problem has weakened. Over the past few years, the homicide rate in Mexico has increased and the general sense of insecurity has grown. Mexico is first among OECD countries in terms of the number of reported murders per 100,000 inhabitants. Business organizations have highlighted the impact this is having on firms. IMCO (2009) estimated the cost per inhabitant to be USD 770 (40\% of which is direct additional costs to families; $55 \%$ economic losses for firms and $5 \%$ related to health). From 1997 to 2007, Mexico spent almost USD 100 billion on tackling insecurity, roughly 3.5 times what the country has invested in infrastructure in the same period through the National Infrastructure Fund (Villalobos, 2008).

While the impact of crime on economic development is difficult to measure precisely, it is widely accepted that respect for the rule of law and low levels of crime are crucial for economic prosperity and societal well being. Over the past few years, Mexican authorities have therefore stepped up their efforts to fight crime, mobilizing extensive resources to ensure a stronger and better equipped law enforcement presence and improving the efficiency of the judicial system. This pro-active approach has had some success, but has also increased the visibility of criminal activity. The effort remains a crucial policy challenge for the government.

The strong measures of the past few years have underlined that fighting crime effectively requires coherent policies across government bodies and levels of government. This includes the relationship, on the one hand, between crime prevention, law enforcement and justice administration, and, on the other hand, between creating opportunities and social development, across local, state and national levels. More effective public policies against crime in Mexico require: (a) to see security and justice as a concern of public policies and not only of the police; (b) to develop evidence-based policymaking in this area, and (c) to be able to give security and justice a strong local grounding.

The multi-level governance issue is particularly important as states have wide powers in the organization of police and courts of law, but also because crime has distinct geographical dynamics. National averages mask strong differences in crime rates across the country. Murder rates are highest in the north-western states such as Chihuahua, Sinaloa and Guerrero, and the rates have been elevated in these regions for more than a decade. Tlaxcala, in the centre, and Yucatán, on the peninsula, have murder rates consistently well below the national average (Figure 21.1). Property crimes, on the other hand, tend to be concentrated in the cities; and the reported crime rate tends to increase in proportion to regional per capita GDP, which explains why figure 21.2 gives a more mixed picture of the distribution of crime across the country. 
Figure 21.1. Intentional homicides per 100,000 inhabitants, 2009 and 2011

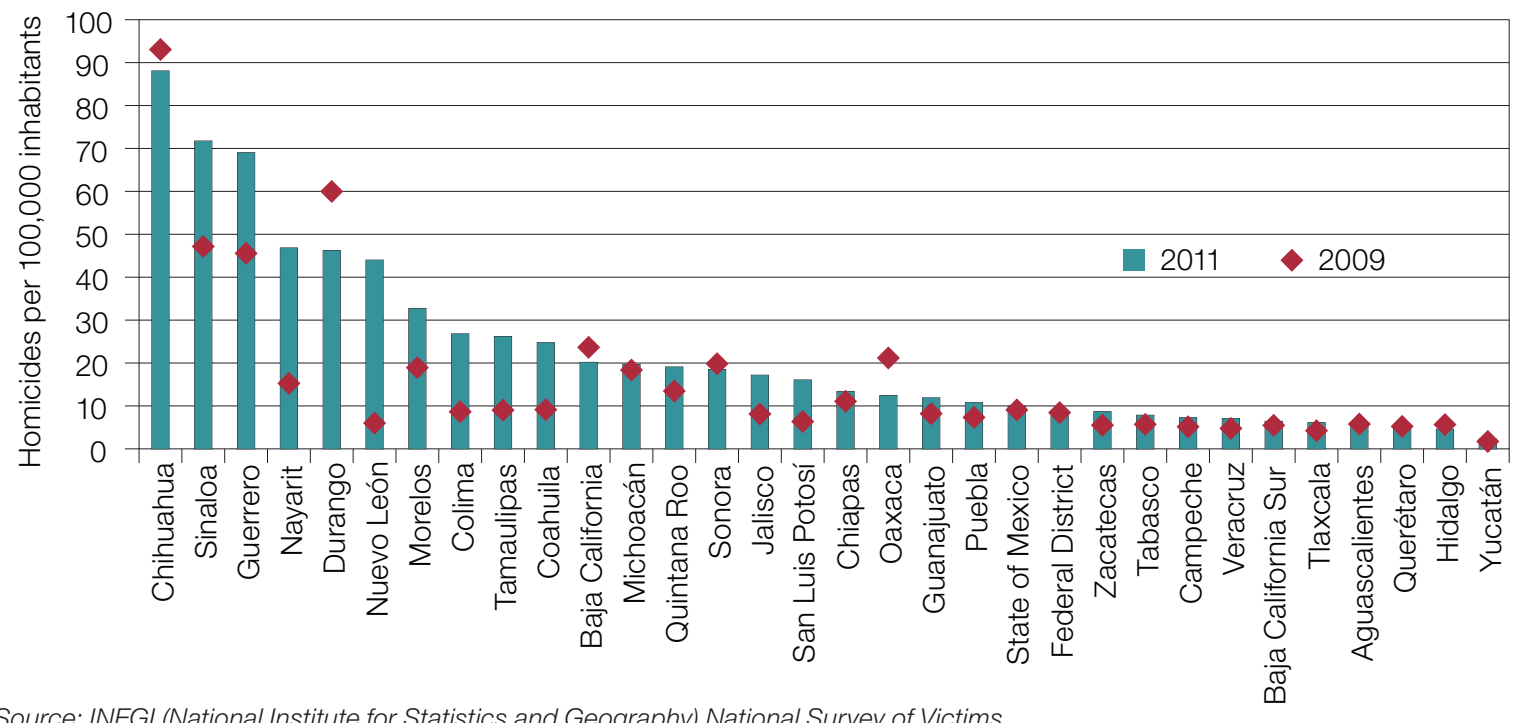

Source: INEGI (National Institute for Statistics and Geography) National Survey of Victims.

\section{Improving data collection and analysis}

The problem for the authorities in dealing with all types of crime is the difficulty of gathering data that is robust and interpretable. For example, willingness to report crimes varies within countries. Research demonstrates that a large number of crimes are never reported: according to the US Bureau of Justice Statistics (2010) only $40 \%$ of property crimes and $49 \%$ of violent crimes were reported to the police. Similar estimates of unreported crimes for Mexico are as high as 90\% (National Survey of Victimization and Perception of Public Safety, ENVIPE, by its Spanish acronym, 2010). Addressing criminal activity depends on active reporting by citizens and business, yet a Gallup survey in 2007 showed that only 37\% of the Mexican public expressed confidence in the country's judicial system and courts. Finally, in Mexico the economic cost associated with starting a criminal process is, or is perceived to be, high and this further discourages reporting. Public policies to prevent crime are thus closely linked to issues of public trust and integrity in the public sector.

Given the importance of improving data and analysis on crime and its impact on the economy, OECD has been working with the Ministry of the Economy and the Mexican Institute for Competitiveness (IMCO, by its Spanish acronym) on a pilot study of evidence-based policymaking on security and justice at the state level in Mexico. This project has developed a preliminary database of indicators by state and can be extended into a broader study that could not only broaden the dataset, but also analyze the capacity of the Mexican states to generate and use evidence to support more effective policies on security and justice. An emphasis on the state level is consistent with a view that recognizes the contribution that controlling criminal activity and increasing security and respect for the rule of law could make to competitiveness at both the state and national levels.

The absence of robust data on crime and its economic impact risks coloring debate on how to tackle insecurity. Some elements are highly exploited in the media, such as the military operations against drug cartels, crossborder trafficking and big money corruption scandals. Yet, much of the lower-profile criminality that affects people's daily lives, often more directly, is never reported. In this context, allocation of resources can easily 
Figure 21.2. Crimes per 100,000 inhabitants as reported in surveys of victims, 2010

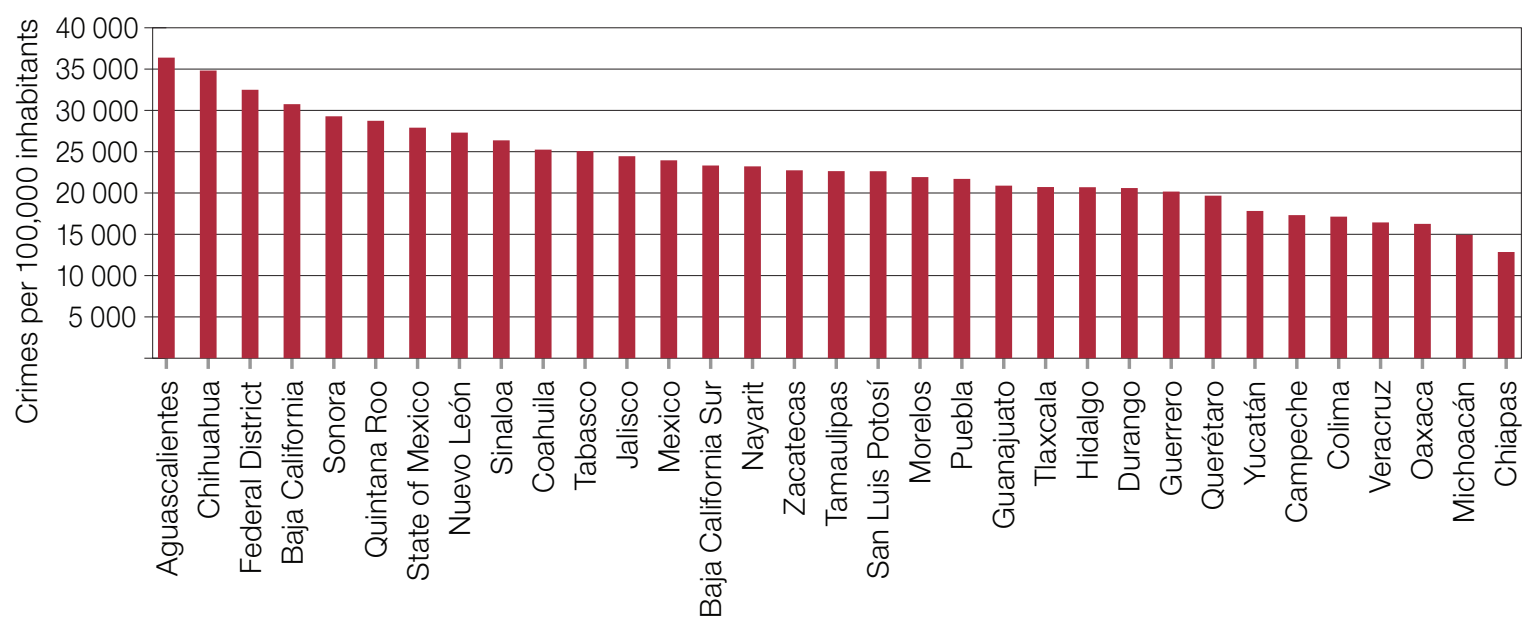

Source: INEGI National Survey of Victims

become skewed. The crucial issue remains, however, how to strengthen and reform institutions related to criminal justice so as to encourage more reporting of crime and more effective prosecution. This in turn will help rebuild trust between citizens and the public authorities.

While the situation remains serious, the past couple of years have witnessed some progress in terms of coordination of policies between the federal level, the states and law enforcement agencies. In addition to high profile operations to break up drug related value chains (e.g. National Governors Conference, CONAGO by its Spanish acronym, 1 and 2), there has also been an effort to better integrate social programmes to address the root causes of criminality. A recent OECD review of Chihuahua highlighted the positive impact of new joint federal-state educational and urban development initiatives such as Todos Somos Juárez. Nonetheless, it will take some time for these programmes to bear fruit and for their impact to be visible in the data.

\section{Key OECD recommendations}

- Mobilise Mexico's statistical and analytical capacity at national and state levels to improve evidence on and quality of security indicators, including better ways to integrate objective and perception measures of the effectiveness of the judicial system and law enforcement by states.

- Develop an evaluation of the performance of criminal justice systems in Mexico designing a framework that takes into account results from previous reforms of justice service.

- Incorporate an assessment of the conditions and incentives for states/localities that could help reforming the justice systems and strengthening institutions. 


\section{ORGANISATION FOR ECONOMIC CO-OPERATION AND DEVELOPMENT}

The OECD is a unique forum where governments work together to address the economic, social and environmental challenges of globalisation. The OECD is also at the forefront of efforts to understand and to help governments respond to new developments and concerns, such as corporate governance, the information economy and the challenges of an ageing population. The Organisation provides a setting where governments can compare policy experiences, seek answers to common problems, identify good practice and work to co-ordinate domestic and international policies.

The OECD member countries are: Australia, Austria, Belgium, Canada, Chile, the Czech Republic, Denmark, Estonia, Finland, France, Germany, Greece, Hungary, Iceland, Ireland, Israel, Italy, Japan, Korea, Luxembourg, Mexico, the Netherlands, New Zealand, Norway, Poland, Portugal, the Slovak Republic, Slovenia, Spain, Sweden, Switzerland, Turkey, the United Kingdom and the United States. The European Union takes part in the work of the OECD.

OECD Publishing disseminates widely the results of the Organisation's statistics gathering and research on economic, social and environmental issues, as well as the conventions, guidelines and standards agreed by its members.

\section{OECD “Better Policies” Series}

The Organisation for Economic Co-operation and Development (OECD) aims to promote better policies for better lives by providing a forum in which governments gather to share experiences and seek solutions to common problems. We work with our 34 members, key partners and over 100 countries to better understand what drives economic, social and environmental change in order to foster the well-being of people around the world. The OECD Better Policies Series provides an overview of the key challenges faced by individual countries and our main policy recommendations to address them. Drawing on the OECD's expertise in comparing country experiences and identifying best practices, the Better Policies Series tailor the OECD's policy advice to the specific and timely priorities of member and partner countries, focusing on how governments can make reform happen. 


\title{
www.oecd.org/mexico
}

\author{
OECD Paris \\ 2, rue André-Pascal, 75775 Paris Cedex 16 \\ Tel.: +33 (0) 145248200
}

